\title{
The Conceptual Research over Low-Switching Modulation Strategy for Matrix Converters with the Coupled Reactors
}

\author{
Pawel Szczepankowski ${ }^{1, *(\mathbb{D})}$, Jaroslaw Luszcz ${ }^{1} \mathbb{D}$, Alexander Usoltsev $^{2} \mathbb{D}$, Natalia Strzelecka ${ }^{3}(\mathbb{D})$ and \\ Enrique Romero-Cadaval 4 (iD) \\ 1 Department of Power Electronics and Electrical Machines, Faculty of Electrical and Control Engineering, \\ Gdansk University of Technology, 80-233 Gdansk, Poland; jaroslaw.luszcz@pg.edu.pl \\ 2 Department of Electrical Engineering and Precision Electro-Mechanical Systems, ITMO University, \\ 197101 St. Petersburg, Russia; uaa@ets.ifmo.ru \\ 3 Department of Ship Automation, Faculty of Electrical Engineering, Gdynia Maritime University, \\ 81-225 Gdynia, Poland; n.strzelecka@we.umg.edu.pl \\ 4 Department of Electrical Electronic and Control Engineering, University of Extremadura, 06006 Badajoz, \\ Spain; eromero@unex.es \\ * Correspondence: pawel.szczepankowski@pg.edu.pl
}

\section{check for}

updates

Citation: Szczepankowski, P.; Luszcz, J.; Usoltsev, A.; Strzelecka, N.; Romero-Cadaval, E. The Conceptual Research over Low-Switching Modulation Strategy for Matrix Converters with the Coupled Reactors. Energies 2021, 14, 675. https://doi.org/10.3390/en14030675

Academic Editors: Tomonobu Senjyu and Ahmed Abu-Siada

Received: 15 December 2020

Accepted: 27 January 2021

Published: 28 January 2021

Publisher's Note: MDPI stays neutral with regard to jurisdictional clai$\mathrm{ms}$ in published maps and institutional affiliations.

Copyright: (C) 2021 by the authors. Licensee MDPI, Basel, Switzerland. This article is an open access article distributed under the terms and conditions of the Creative Commons Attribution (CC BY) license (https:// creativecommons.org/licenses/by/ $4.0 /)$.

\begin{abstract}
In this paper, different Pulse Width Modulation (PWM) strategies for operating with a low-switching frequency, a topology that combines Conventional Matrix Converters (CMCs), and Coupled Reactors (CRs) are presented and discussed. The principles of the proposed strategies are first discussed by a conceptual analysis and later validated by simulation. The paper shows how the combination of CMCs and CRs could be of special interest for sharing the current among these converters' modules, being possible to scale this solution to be a modular system. Therefore, the use of coupled reactors allows one to implement phase shifters that give the solution the ability to generate a stair-case load voltage with the desired power quality even the matrix converters are operated with a low-switching frequency close to the grid frequency. The papers also address how the volume and weight of the coupled reactors decrease with the growth of the fundamental output frequency, making this solution especially appropriate for high power applications that are supplied at high $\mathrm{AC}$ frequencies (for example, in airport terminals, where a supply of $400 \mathrm{~Hz}$ is required).
\end{abstract}

Keywords: matrix converter; pulse width modulation; multipulse voltage converter; nearest voltage modulation; pulse width regulation; low-switching modulation technique; multipulse matrix converter with coupled reactors

\section{Introduction}

The energy conversion in the AC grid realized by power electronics devices always needs efficiency, reliability, and compatibility [1]. The first element is significantly affected by conduction and switching losses of the applied semiconductors. Reliability can lead to the elimination of weak construction elements, which most often fail. Demands for Electromagnetic Intereference (EMI) compatibility have also increased in recent years [2]. Moreover, the ecological aspect of the energy-saving cannot be omitted today [3,4]. The paper proposes the Multipulse Matrix Converter with Coupled Reactors (MMCCR) [5-7] as an alternative solution to the Variable Frequency Drive (VFD) based on the classic AC-DC-AC topology. The use of PWM techniques with a high-switching frequency in these applications can lead to significant dynamic losses but it is required to maintain the good quality of the generated AC voltage.

Reduction of switching frequency of the power electronic devices without a significant decreases of the output voltage quality can be achieved by using multilevel AC-DC-AC topology [8]. This device converts an AC input voltage into the DC voltage and the voltage smoothing bulk electrolytic capacitor in the DC-link circuit is required for this purpose. 
Capacitor bank stores the energy, which is converted back into AC voltage with the desired frequency using the PWM inverter [9-12]. Another concept of the AC voltage quality improvement uses magnetic elements and most often involves the use of multiphase transformers with an appropriately designed winding configuration [13]. This solution is characterized by low switching frequency but the main disadvantage of such approach related to transformers is cost. Without a doubt, the overall cost is driven by the transformer price, which can be reduced by applying instead the coupled reactors arrangement [14]. The main advantage of using coupled reactors is a significant size reduction, thus for the same load power coupled reactors will be designed for power around five times lower then transformer [15].

The Conventional Matrix Converter (CMC), in comparison with the classic AC-DC$\mathrm{AC}$ frequency converter, has certain individual features that determine the innovation of such a solution [16-19]. This converter is fully bidirectional and operates without a large capacitor, with different frequencies at inputs and outputs of the system. Moreover, a matrix converter allows the power factor regulation [20]. The topology, which contains four matrix converters with coupled reactors, has been already demonstrated in literature [21] but without the inclusion of the amplitude voltage control. The proposed converters arrangement can be used in a turbine generator system equipped with a high-speed synchronous generator with permanent magnets. In such a system, the turbine transmits torque to the shaft of the electric machine directly or through a mechanical transmission, as illustrated in Figure 1.

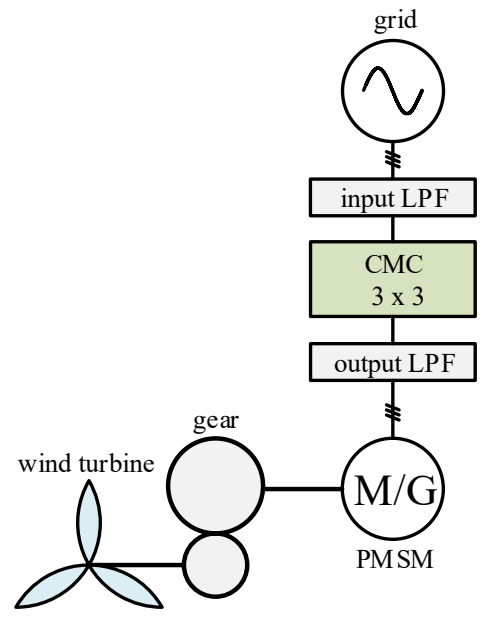

(a)

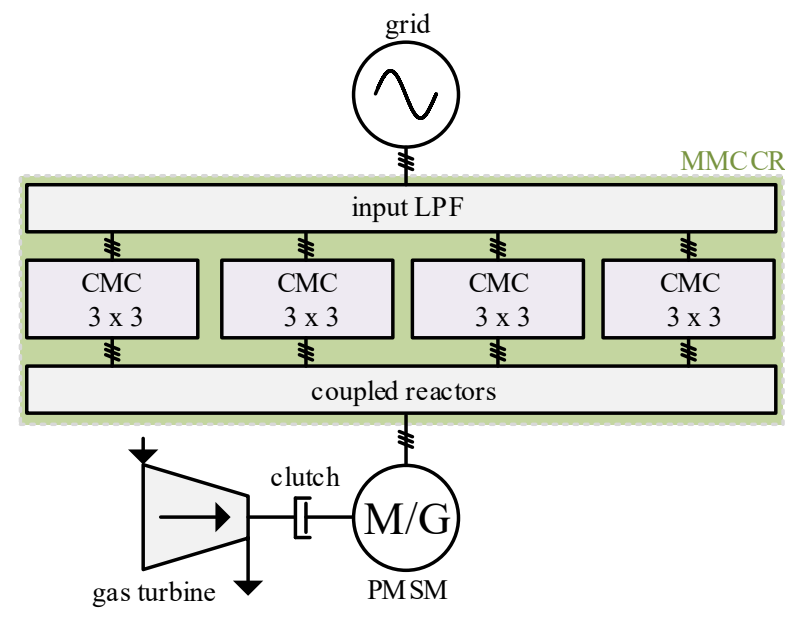

(b)

Figure 1. Examples of simplified application diagrams of turbines: (a) a wind turbine with a gear, (b) a gas turbine with a clutch. Conventional Matrix Converter (CMC) $3 \times 3$-conventional matrix converter with 3 inputs and 3 outputs, M/G-motor/generator, LPF-low-pass filter.

The synchronous generator produces AC voltage with a frequency dependent on the rotational speed of the turbine [22]. To transfer the obtained energy to the grid, the generated voltage should be converted and synchronized with the three-phase source. This task is performed with the use of power electronic converters, by the matrix converter in particular. Both mechanical transmission using the gear and converter losses determine the efficiency of the system. The smaller the difference between the input and output speed in the mechanical transmission, the smaller the losses [23]. Therefore, a modulation method which decreases the switching number in power converters with a small impact on the quality of voltage and current waveforms are desired. High-speed electrical machines are characterized by greater overall power than machines made for standard speeds, higher frequency of voltage at the terminals, and higher current [24].

Another factor legitimizing the frequency increase is the possibility of eliminating large electrolytic capacitors, which are the fastest deteriorating element in converters. This 
can be done by using a matrix converter that does not require such energy storage at all. Unfortunately, the use of standard power electronic switches and classic matrix converter topologies is limited by the upper allowable switching frequency. Therefore, the choice of such a solution may be resulting in a significant increase in the complexity of passive filters and a limit the converter dynamic, which is essential in small microgrids with distributed generation elements.

The paper proposes to use four matrix converters operating in parallel due to the modularity of such a solution and the increase in the range of operating currents. Due to new conditions, such as higher voltage frequency, modular nature of the topology and no requirement of galvanic isolation, the use of the coupled reactors circuits is an interesting idea. In addition, the leakage inductance of such reactors can also be used in controlling the power flow between the generator and the grid. The set and arrangement of the base vectors in the alpha-beta plain allow for the implementation of modulation methods with a lower switching frequency compared to Space-Vector Pulse Width Modulation (SVPWM) but with relatively good waveform quality. The switching frequency is equal to the generator frequency in particular. The purpose of conceptual research is shortly presented in the next subsection.

A multiphase transformer for multipulse rectifiers and similar topologies with the coupled reactors are known solutions. However, such an approach is mostly applied to systems that operate with the grid frequency. Considering the price of copper, these solutions are relatively expensive. The dimensions, as well as the price of these components, decrease with increasing nominal frequency. Thus, high-speed electrical machines seem to be the perspective area for the proposed converter topology. The SVPWM modulation allows for linear adjustment of both frequency and amplitude. However, it requires power electronic switches to operate at high frequency. The efficiency of that solution can be improved using the hybrid strategy of modulation. Consider the simplified gas turbine work profile shown in Figure 2.

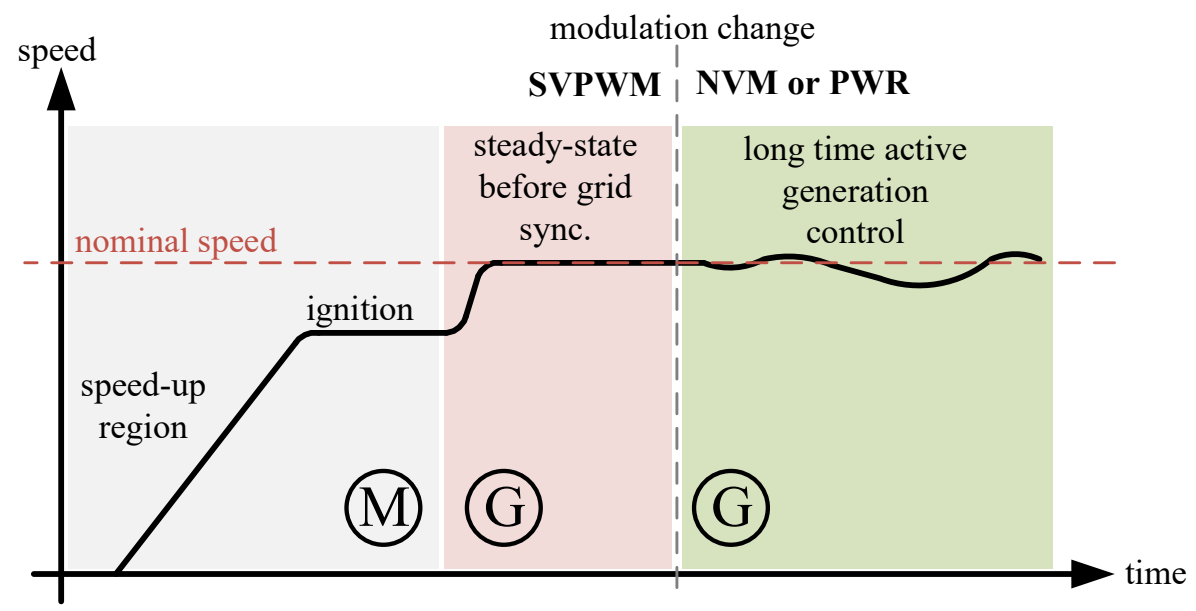

Figure 2. The simplified speed profile of the gas turbine: M-PMSM operates as a motor, G-PMSM operates as a generator, SVPWM-high-frequency modulation method based on the space-vector concept, Nearest Vector Modulation (NVM) and Pulse Width Modulation (PWR)—the low-switching frequency type of PWM modulation.

In the speed-up region, the required energy is supplied from the utility grid through the inverter converter controlled using the SVPWM algorithm. This modulation is used until the synchronisation with the grid. When the speed is stable, the long time active generation control begins, which can be performed using the proposed low-switching modulation approach. The main goal of the authors of the publication was to develop such modulation and preliminary simulation studies. 


\subsection{The Discrete Projection of Voltage Vectors}

The essence of the solution is to achieve a very low operating frequency of power electronic switches. The forming of the output voltage in the proposed group of converters, while maintaining the power switches in the lowest operating frequency, can be formally presented as an effect of discrete projection of the reference vector, as shown in Figure 3.
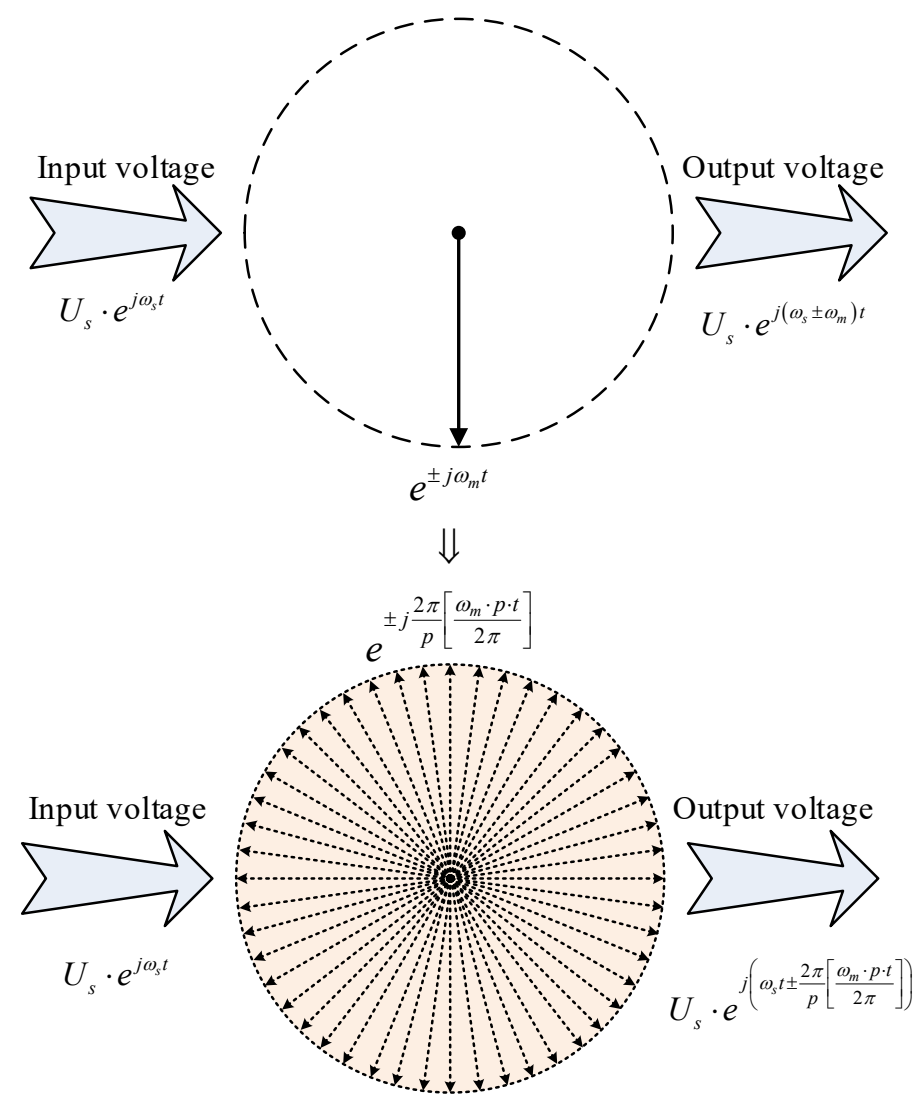

Figure 3. The general discrete reference vector projection concept: $U_{s}-$ voltage amplitude, $\omega_{s}$ and $\omega_{m}$ pulsations, $p$ a number of discrete voltage vectors [7].

Applying the idea of the projection in solutions composed of conventional $3 \times 3$ matrix converters, a multipulse output voltage can be obtained. Figure 4 shows a conventional matrix topology as the 3-pulse system, which does not contain any coupled reactors yet. The need of using the coupled reactors appears in the 6-pulse system. Such a converter is shown in Figure 5.

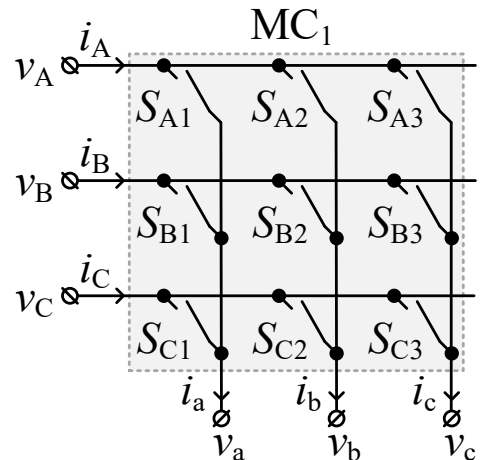

(a)

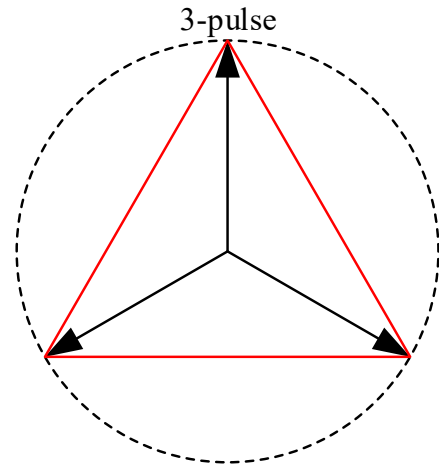

(b)

Figure 4. Conventional matrix converter as a 3-pulse system: (a) schematic diagram, (b) the voltages discrete projection. 


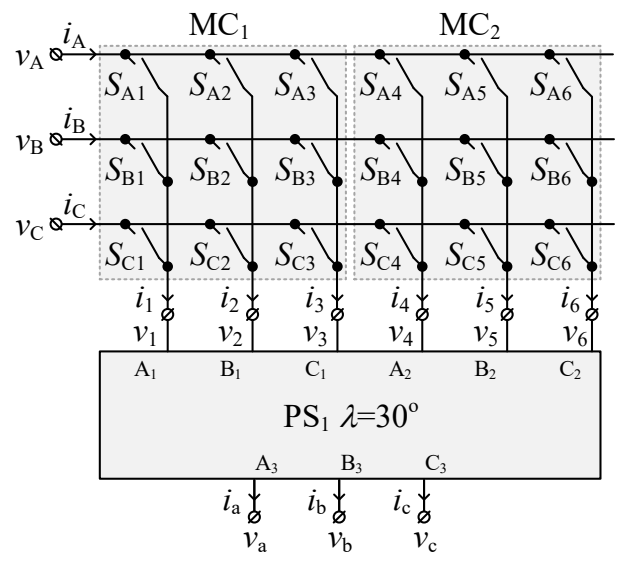

(a)

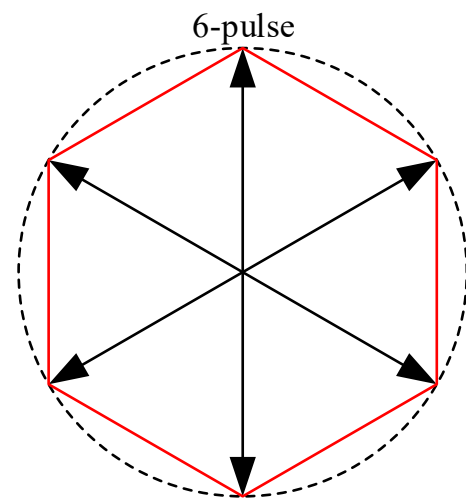

(b)

Figure 5. Two conventional matrix converters make the 6-pulse system: (a) schematic diagram, (b) the voltages discrete projection.

\subsection{Coupled Reactors}

Both solutions, 6-pulse and 12-pulse, require an appropriately coupled reactors arrangement [25]. The proposed topology, shown in Figure 6a, contains 36 bidirectional switches $S_{\mathrm{A} 1}-S_{\mathrm{C} 12}$, which are elements of four 4 matrix converters $\mathrm{CMC}_{1}-\mathrm{CMC}_{4}$ and 3 Phase Shifters (PS) $\mathrm{PS}_{1}, \mathrm{PS}_{2}$ and $\mathrm{PS}_{3}$ respectively. The connection diagram of the simulation model of a three-phase type coupled reactor is shown in Figure 7.

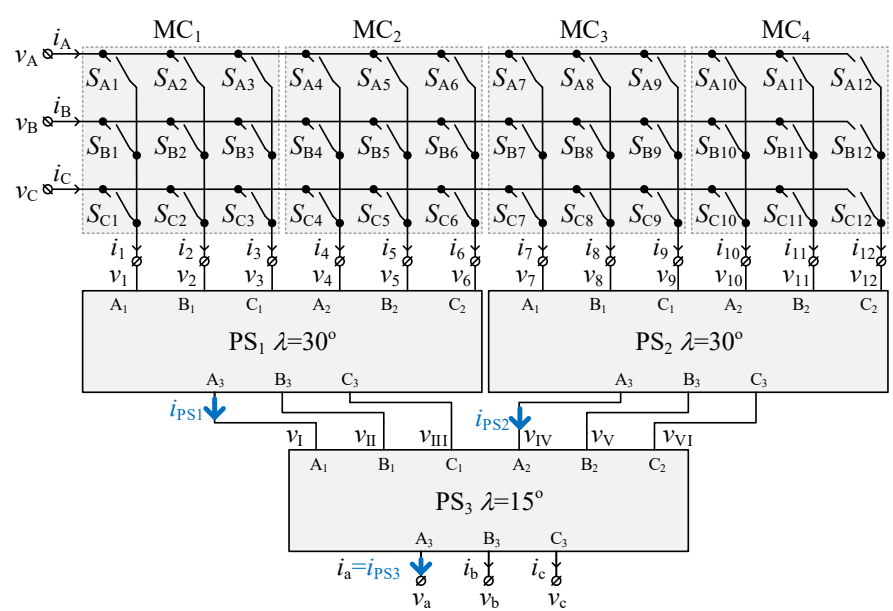

(a)

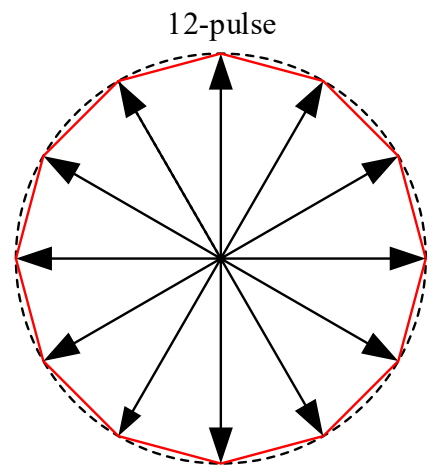

(b)

Figure 6. Four conventional matrix converters make the 12-pulse system: (a) schematic diagram, (b) the voltages discrete projection.

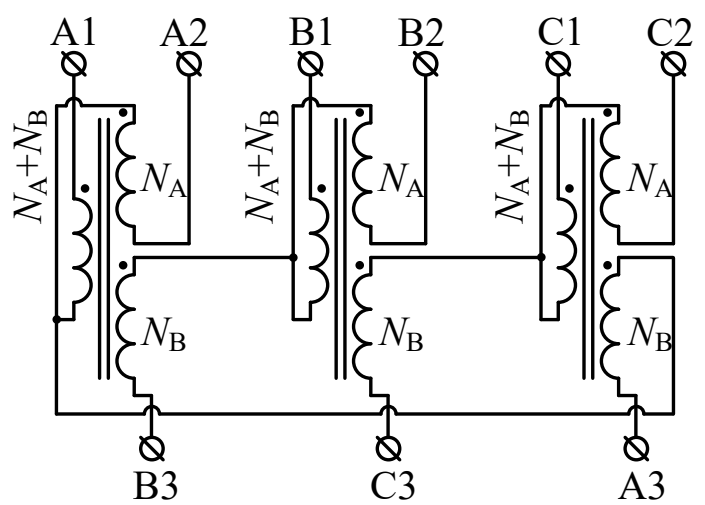

Figure 7. Phase Shifter schematic. 
To obtain the desired phase shift angle $\lambda$ the ratio of turns number $N_{\mathrm{A}}$ to $N_{\mathrm{B}}$, should meet the following condition

$$
n_{\mathrm{AB}}=\frac{N_{\mathrm{A}}}{N_{\mathrm{B}}}=\frac{\sin \left(\frac{4 \pi}{p_{\mathrm{n}}}-\lambda\right)}{\sin (\lambda)}
$$

where

$p_{\mathrm{n}}$ is the number of pulses of a given system and in the discussed example takes 12 ,

$\lambda$ is a desired phase shift angle,

$N_{\mathrm{A}}$ and $N_{\mathrm{B}}$ is the ratio of turns number.

An example turns number for two shift angles are presented in Tables 1 and 2. The final number of windings depends on the adopted design parameters, in particular on the power of the system and the reactors' voltage spectrum. This aspect is not covered in this article.

Table 1. Turns number for shift angle equal to $30^{\circ}$ (conversion values).

\begin{tabular}{cccc}
\hline$N_{\mathrm{A}}+N_{\mathbf{B}}$ & $<\mathbf{1 0 0}$ & $<\mathbf{3 0 0}$ & $<\mathbf{1 0 0 0}$ \\
\hline$N_{\mathrm{A}}$ & 15 & 56 & 209 \\
$N_{\mathrm{B}}$ & 15 & 56 & 209 \\
\hline
\end{tabular}

Table 2. Turns number for shift angle equal to $15^{\circ}$ (conversion values).

\begin{tabular}{cccc}
\hline$N_{\mathbf{A}}+N_{\mathbf{B}}$ & $<\mathbf{1 0 0}$ & $<\mathbf{3 0 0}$ & $<\mathbf{1 0 0 0}$ \\
\hline$N_{\mathrm{A}}$ & 41 & 153 & 571 \\
$N_{\mathrm{B}}$ & 15 & 56 & 209 \\
\hline
\end{tabular}

The values of the turns number determine not only the shift angle but also certain properties of the presented topology, such as the amount of reactive power circulating between the coupled three-phase reactors and also the value of the maximum amplitudes of the output phase voltage. For simplicity of the rest text, let us assume that magnetic elements in circuits shown in Figure 7 are linear and lossless, and bidirectional power switches are ideal. The further part of the paper concerns the 12-pulse system only. The article is organised as follows. The space of the rotating vectors for 12-pulse MMCCR and the load voltage synthesis basic are presented in Section 2. While the control of output voltage amplitude using the low switching frequency modulation is proposed in the next section. Simulation results are shown and discussed in Section 4.

\section{The Space of the Rotating Vectors for 12-Pulse MMCCR}

The switch state is 0 , if it is switched off, and takes unity if it is switched on. The states of all bidirectional switches can be defined by four switch state matrices $\mathbf{S}_{\mathrm{MC1}}-\mathbf{S}_{\mathrm{MC}}$ expressed as follows

$$
\begin{aligned}
& \mathbf{s}_{\mathrm{MC} 1}=\left[\begin{array}{lll}
S_{\mathrm{A} 1} & S_{\mathrm{B} 1} & S_{\mathrm{C} 1} \\
S_{\mathrm{A} 2} & S_{\mathrm{B} 2} & S_{\mathrm{C} 2} \\
S_{\mathrm{A} 3} & S_{\mathrm{B} 3} & S_{\mathrm{C} 3}
\end{array}\right] \\
& \mathbf{s}_{\mathrm{MC} 2}=\left[\begin{array}{lll}
S_{\mathrm{A} 4} & S_{\mathrm{B} 4} & S_{\mathrm{C} 4} \\
S_{\mathrm{A} 5} & S_{\mathrm{B} 5} & S_{\mathrm{C} 5} \\
S_{\mathrm{A} 6} & S_{\mathrm{B} 6} & S_{\mathrm{C} 6}
\end{array}\right] \\
& \mathbf{s}_{\mathrm{MC} 3}=\left[\begin{array}{lll}
S_{\mathrm{A} 7} & S_{\mathrm{B} 7} & S_{\mathrm{C} 7} \\
S_{\mathrm{A} 8} & S_{\mathrm{B} 8} & S_{\mathrm{C} 8} \\
S_{\mathrm{A} 9} & S_{\mathrm{B} 9} & S_{\mathrm{C} 9}
\end{array}\right]
\end{aligned}
$$




$$
\mathbf{S}_{\mathrm{MC} 4}=\left[\begin{array}{lll}
S_{\mathrm{A} 10} & S_{\mathrm{B} 10} & S_{\mathrm{C} 10} \\
S_{\mathrm{A} 11} & S_{\mathrm{B} 11} & S_{\mathrm{C} 11} \\
S_{\mathrm{A} 12} & S_{\mathrm{B} 12} & S_{\mathrm{C} 12}
\end{array}\right]
$$

The modulation techniques presented in this article were developed for a system containing four conventional matrix converters. The proposed approach uses only six switch states among the 27 available. These selected vectors belong to the group of the rotating vectors [16]. Three of them rotate in a clockwise direction (Table 3), while the remaining three are counterclockwise (Table 4). In general, two collections of switch states can be proposed for the modulation. The first collection contains all combinations, which utilise the counterclockwise rotating voltage vectors. These states are described in Appendix A. The second collection, presented in Appendix A, comprises the clockwise rotating vectors. In summary, the total number of switch state combinations for MMCCR is equal to $3^{4}$.

Table 3. Allowed $\mathbf{S}_{\mathrm{MC} p}$ switch states.

\begin{tabular}{ccc}
\hline \multicolumn{3}{c}{ States $\mathbf{S}_{\mathrm{MC} p}$} \\
\hline $\mathbf{S}_{\mathrm{I} p}$ & $\mathbf{S}_{\mathrm{II} p}$ \\
\hline$\left[\begin{array}{lll}0 & 0 & 1 \\
0 & 1 & 0 \\
1 & 0 & 0\end{array}\right]$ & {$\left[\begin{array}{lll}0 & 1 & 0 \\
1 & 0 & 0 \\
0 & 0 & 1\end{array}\right]$} & {$\left[\begin{array}{lll}1 & 0 & 0 \\
0 & 0 & 1 \\
0 & 1 & 0\end{array}\right]$} \\
\hline
\end{tabular}

Table 4. Allowed $\mathbf{S}_{\mathrm{MCn}}$ switch states.

\begin{tabular}{ccc}
\hline \multicolumn{3}{c}{ States $\mathbf{S}_{\mathrm{MC} \boldsymbol{n}}$} \\
\hline $\mathbf{S}_{\mathrm{I} \boldsymbol{n}}$ & $\mathrm{S}_{\mathrm{II} \boldsymbol{n}}$ \\
\hline$\left[\begin{array}{lll}0 & 0 & 1 \\
1 & 0 & 0 \\
0 & 1 & 0\end{array}\right]$ & {$\left[\begin{array}{lll}0 & 1 & 0 \\
0 & 0 & 1 \\
1 & 0 & 0\end{array}\right]$} & {$\left[\begin{array}{lll}1 & 0 & 0 \\
0 & 1 & 0 \\
0 & 0 & 1\end{array}\right]$} \\
\hline
\end{tabular}

The output voltage values for each converter depicted in Figure 7 can be calculated as follows

$$
\begin{aligned}
& {\left[\begin{array}{lll}
v_{1} & v_{2} & v_{3}
\end{array}\right]^{\mathrm{T}}=\mathbf{S}_{\mathrm{MC1}} \cdot\left[\begin{array}{lll}
v_{\mathrm{A}} & v_{\mathrm{B}} & v_{\mathrm{C}}
\end{array}\right]^{\mathrm{T}}} \\
& {\left[\begin{array}{lll}
v_{4} & v_{5} & v_{6}
\end{array}\right]^{\mathrm{T}}=\mathbf{S}_{\mathrm{MC} 2} \cdot\left[\begin{array}{lll}
v_{\mathrm{A}} & v_{\mathrm{B}} & v_{\mathrm{C}}
\end{array}\right]^{\mathrm{T}}} \\
& {\left[\begin{array}{lll}
v_{7} & v_{8} & v_{9}
\end{array}\right]^{\mathrm{T}}=\mathbf{S}_{\mathrm{MC} 3} \cdot\left[\begin{array}{lll}
v_{\mathrm{A}} & v_{\mathrm{B}} & v_{\mathrm{C}}
\end{array}\right]^{\mathrm{T}}} \\
& {\left[\begin{array}{lll}
v_{10} & v_{11} & v_{12}
\end{array}\right]^{\mathrm{T}}=\mathbf{S}_{\mathrm{MC} 4} \cdot\left[\begin{array}{lll}
v_{\mathrm{A}} & v_{\mathrm{B}} & v_{\mathrm{C}}
\end{array}\right]^{\mathrm{T}}}
\end{aligned}
$$

According to the shown topology scheme, the matrix converters' output is connected with the PS PS 1 and $\mathrm{PS}_{2}$ respectively. A simple circuit analysis, shown in Figure 7, leads to the following voltage synthesis matrices

$$
\begin{aligned}
& {\left[\begin{array}{c}
v_{\mathrm{I}} \\
v_{\mathrm{II}} \\
v_{\mathrm{III}}
\end{array}\right]=\left[\begin{array}{lll}
v_{2} & v_{2}-v_{5} & v_{1}-v_{4} \\
v_{3} & v_{3}-v_{6} & v_{2}-v_{5} \\
v_{1} & v_{1}-v_{4} & v_{3}-v_{6}
\end{array}\right]\left[\begin{array}{c}
1 \\
-k_{1} \\
-k_{2}
\end{array}\right]} \\
& {\left[\begin{array}{c}
v_{\mathrm{IV}} \\
v_{\mathrm{V}} \\
v_{\mathrm{VI}}
\end{array}\right]=\left[\begin{array}{lll}
v_{8} & v_{8}-v_{11} & v_{7}-v_{10} \\
v_{9} & v_{9}-v_{12} & v_{8}-v_{11} \\
v_{7} & v_{7}-v_{10} & v_{9}-v_{12}
\end{array}\right]\left[\begin{array}{c}
1 \\
-k_{1} \\
-k_{2}
\end{array}\right]}
\end{aligned}
$$

where the values of coefficients $k_{1}$ and $k_{2}$ can be calculated using the number of turns listed in Table 1

$$
k_{1}=\frac{N_{\mathrm{A}\left(30^{\circ}\right)}+N_{\mathrm{B}\left(30^{\circ}\right)}}{2 N_{\mathrm{A}\left(30^{\circ}\right)}+N_{\mathrm{B}\left(30^{\circ}\right)}} \quad k_{2}=\frac{N_{\mathrm{B}\left(30^{\circ}\right)}}{2 N_{\mathrm{A}\left(30^{\circ}\right)}+N_{\mathrm{B}\left(30^{\circ}\right)}}
$$


The final output voltage synthesis is realised by the third PS PS 3 , according to the equation

$$
\left[\begin{array}{c}
v_{\mathrm{a}} \\
v_{\mathrm{b}} \\
v_{\mathrm{c}}
\end{array}\right]=\left[\begin{array}{ccc}
v_{\mathrm{II}} & v_{\mathrm{II}}-v_{\mathrm{V}} & v_{\mathrm{I}}-v_{\mathrm{IV}} \\
v_{\mathrm{III}} & v_{\mathrm{III}}-v_{\mathrm{VI}} & v_{\mathrm{II}}-v_{\mathrm{V}} \\
v_{\mathrm{I}} & v_{\mathrm{I}}-v_{\mathrm{IV}} & v_{\mathrm{III}}-v_{\mathrm{VI}}
\end{array}\right]\left[\begin{array}{c}
1 \\
-k_{3} \\
-k_{4}
\end{array}\right]
$$

where, as before, the coefficients $k_{3}$ and $k_{4}$ values can be calculated using the number of turns listed in Table 2 resulting in the following formula

$$
k_{3}=\frac{N_{\mathrm{A}\left(15^{\circ}\right)}+N_{\mathrm{B}\left(15^{\circ}\right)}}{2 N_{\mathrm{A}\left(15^{\circ}\right)}+N_{\mathrm{B}\left(15^{\circ}\right)}} \quad k_{4}=\frac{N_{\mathrm{B}\left(15^{\circ}\right)}}{2 N_{\mathrm{A}\left(15^{\circ}\right)}+N_{\mathrm{B}\left(15^{\circ}\right)}}
$$

Assuming that the MMCCR is supplied by a three-phase balanced AC voltage source and the load is symmetrical, the space vector $\alpha-\beta$ coordinates can be obtained using the simplified amplitude invariant Clarke transform

$$
\begin{aligned}
& v_{\alpha}=v_{\mathrm{a}} \\
& v_{\beta}=\frac{v_{\mathrm{b}}-v_{\mathrm{c}}}{\sqrt{3}}
\end{aligned}
$$

The space-vector diagram for $\mathbf{S}_{\mathrm{MC} p}$ switch state types, and $n_{\mathrm{AB} 1}=n_{\mathrm{AB} 2}=209 / 209$, $n_{\mathrm{AB} 3}=571 / 209$, is shown in Figure 8 . While the space-vector diagram for $\mathbf{S}_{\mathrm{MC} n}$ switch state types is illustrated in Figure 9. The obtained space-vector diagrams are not stationary and rotate with the frequency of the grid voltage.

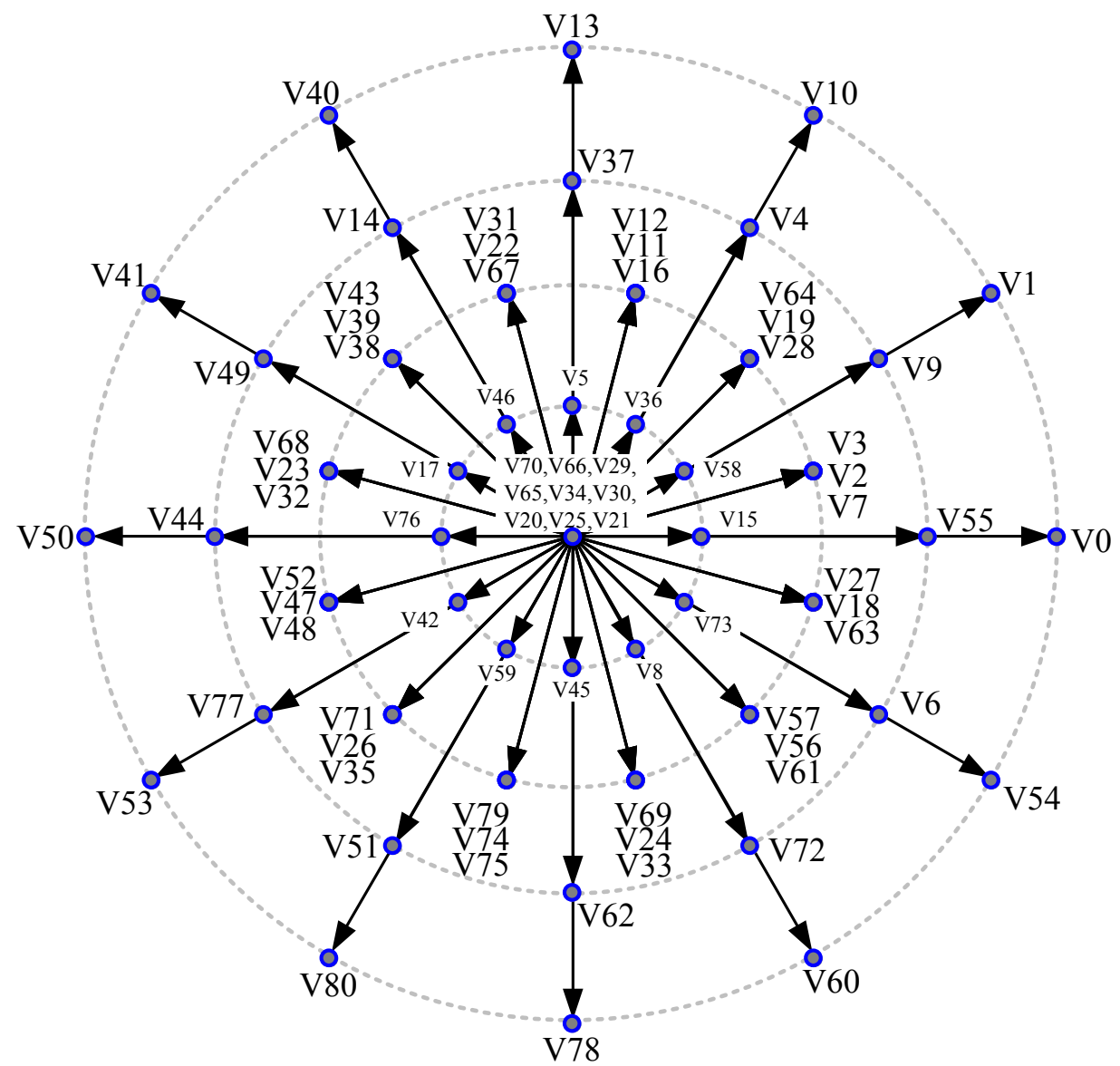

Figure 8. The space-vector diagram for $\mathbf{S}_{\mathrm{MC} p}$ switch states. 


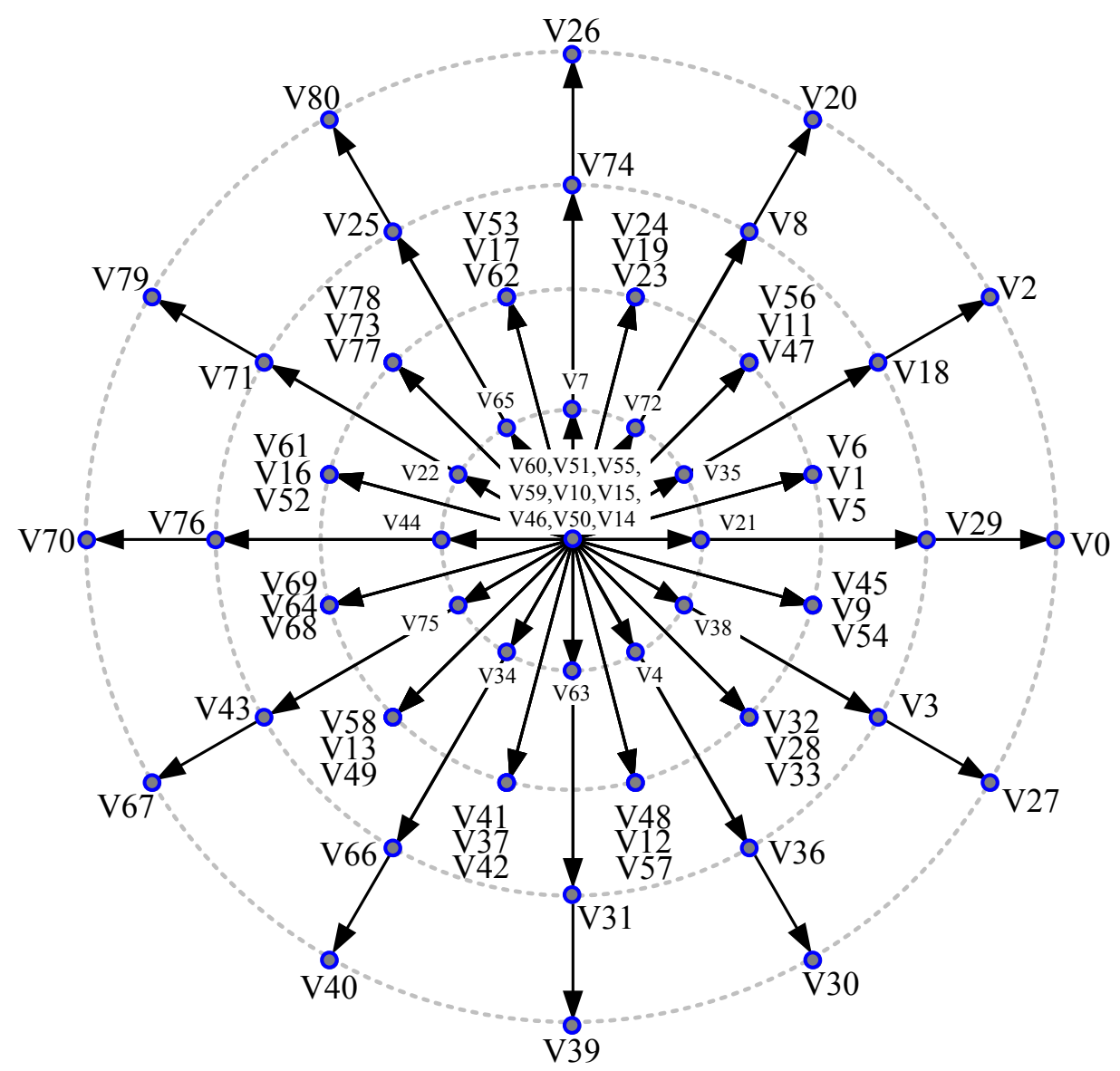

Figure 9. The space-vector diagram for $\mathbf{S}_{\mathrm{MC} n}$ switch states.

\section{The Control of Output Voltage Amplitude Using the Low Switching Frequency Modulation}

This section proposes two low switching frequency modulation methods-the Pulse Width Regulation PWR and Nearest Vector Modulation NVM. Both methods are successfully verified using PSIM simulation software. The load voltage is represented by one vector, which is rotating on the stationary, orthogonal $\alpha-\beta$ reference frame. This frame is built from the basic voltage vectors correspond to the switches states. The total number of switch state is equal to the $M^{N}$, where $M$ is a number of allowed state combination across the one commutation cell, while $N$ is a number of cells. Thus theoretically the total number of switch states is $3^{12}$ for the proposed converter topology. Due to the concept of magnetically coupled using the coupled reactors presented in [25] only the rotating vectors are allowed. The stationary and the zero vectors from the conventional matrix converter space-vector frame are not suitable for that kind of the reactors' circuit. There are six rotating vectors allowed for each of the conventional matrix converters. Two collections can be distinguished-the first covers vectors, that rotate clockwise-while the second set represents vectors rotate counterclockwise. Thus, if the number of the conventional matrix converter is equal to 4, as shown in Figure 6 the total number of selected vectors is reduced to $3^{4}$. The load voltage can be synthesised using a variety of switch states sequence. However, due to the requirement to minimise losses during modulation, only the nearest vectors are applied within the modulation period.

\subsection{Pulse Width Regulation}

The synthesis of voltages in the MMCCR with modular structure can be directed to the high efficiency of the power conversion system also oriented to decreasing the number of switching. However, the operating frequency should be chosen so as to preserve the multipulse nature of the generated phase voltages with the assumption of the amplitude 
output voltage regulation. Considering the vectors arrangement shown in Figure 10, the vectors V0-V54 belong to the outer circle with radius is equal to $1.0 \mathrm{p} . \mathrm{u}$., while the vectors V55-V6 are located on an inner circle with radius of 0.732 p.u.. The shown reference voltage vector $\mathrm{V}_{\mathrm{REF}}$ lies exactly between vectors $\mathrm{V} 9$ and $\mathrm{V} 1$ area, which refers to a sector 2 in propose modulation scheme. To obtain the symmetry effect of the states sequence in the time window corresponding to the modulation period $\mathrm{T}_{\mathrm{PWR}}$, the three-step switch states sequence has been proposed. The first three sequences are shown in Table 5. The PWR duty cycles, for each sector, can be calculated as follows

$$
\begin{aligned}
d_{\mathrm{H}} & =\frac{\mathrm{V}_{\mathrm{REF}}-\mathrm{V}_{\mathrm{L}}}{\mathrm{V}_{\mathrm{H}}-\mathrm{V}_{\mathrm{L}}} \\
d_{\mathrm{L}} & =1-d_{\mathrm{H}}
\end{aligned}
$$

where $\mathrm{V}_{\mathrm{H}}=1.0, \mathrm{~V}_{\mathrm{L}}=0.732$, and $d_{\mathrm{H}}$ corresponds to the longer vector. An example waveform of the output voltage is shown in Figure 11.

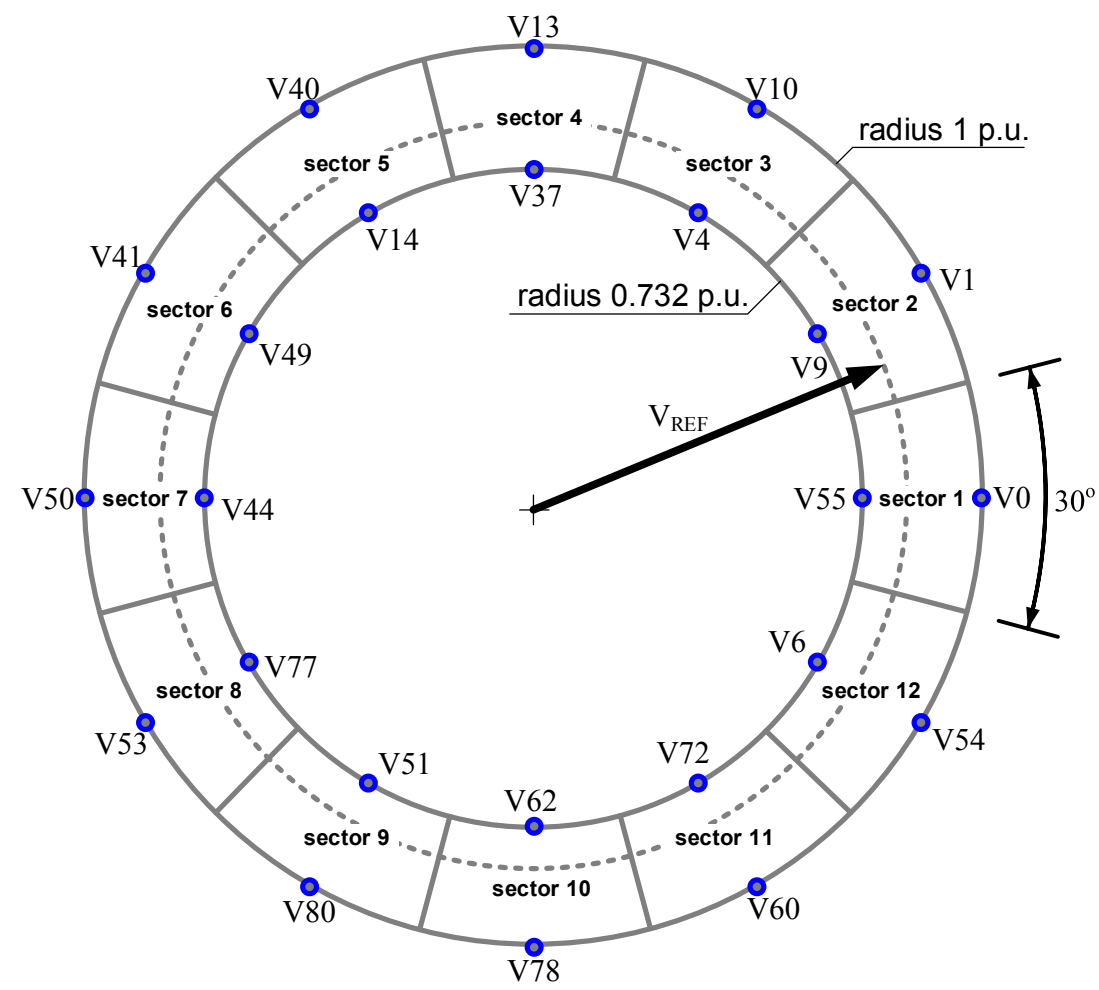

Figure 10. The PWR modulation workspace for $\mathbf{S}_{\mathrm{MC} p}$ switch states.

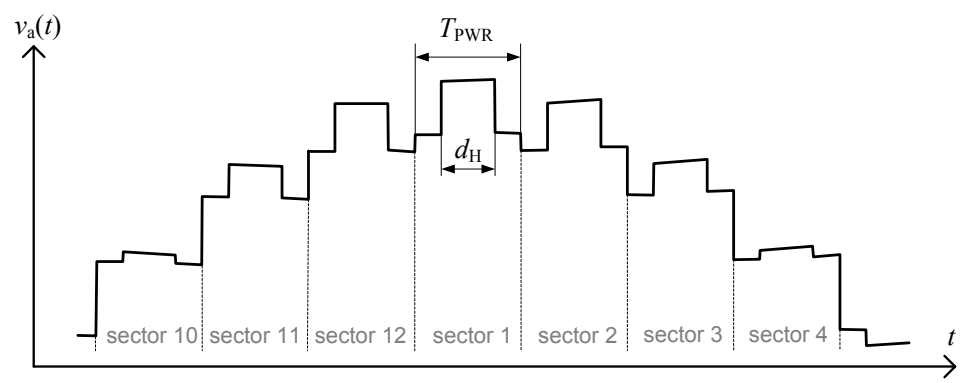

Figure 11. Fragment of phase voltage waveform for the PWR modulation using the $\mathbf{S}_{\mathrm{MC} n}$ states.

The coordinates of the reference output voltage $V_{\text {REF }}$ can be defined according to the selected type of switch state matrices. For selected $\mathbf{S}_{\mathrm{MC} n}$ the $\alpha \beta$ coordinates of the $\mathrm{V}_{\mathrm{REF}}$, can be calculated

$$
\begin{aligned}
& v_{\alpha}^{*}=q \cdot \cos \left(\omega_{\mathrm{i}} \cdot\left(k_{\mathrm{f}}+2\right) \cdot t\right) \\
& v_{\beta}^{*}=q \cdot \sin \left(\omega_{\mathrm{i}} \cdot\left(k_{\mathrm{f}}+2\right) \cdot t\right)
\end{aligned}
$$


while for $\mathbf{S}_{\mathrm{MC} p}$ we obtain

$$
\begin{aligned}
& v_{\alpha}^{*}=q \cdot \cos \left(\omega_{\mathrm{i}} \cdot\left(k_{\mathrm{f}}-2\right) \cdot t+\frac{2 \pi}{3}\right) \\
& v_{\beta}^{*}=q \cdot \sin \left(\omega_{\mathrm{i}} \cdot\left(k_{\mathrm{f}}-2\right) \cdot t+\frac{2 \pi}{3}\right)
\end{aligned}
$$

where

$$
\begin{aligned}
& v_{\alpha}^{*} \text {-reference } \alpha \text { coordinate, } \\
& v_{\beta}^{*} \text {-reference } \beta \text { coordinate, } \\
& \omega_{\mathrm{i}} \text {-input voltage pulsation, } \\
& k_{\mathrm{f}}=\omega_{\mathrm{o}} / \omega_{\mathrm{i}}-\text { pulsation ratio, and } \\
& q=V_{\mathrm{REF}} / V_{\mathrm{i}} \text { is the voltage transfer ratio. }
\end{aligned}
$$

Table 5. Example the switch states sequences in the first 3 sectors.

\begin{tabular}{ccccc}
\hline Type & $n_{\mathrm{AB} 3}$ & Sector 1 & Sector 2 & Sector 3 \\
\hline $\mathrm{S}_{\mathrm{MC} p}$ & $571 / 209$ & V55-V0-V55 & V9-V1-V9 & V4-V10-V4 \\
$\mathrm{S}_{\mathrm{MCn}}$ & $571 / 209$ & V29-V0-V29 & V18-V2-V18 & V8-V20-V8 \\
\hline
\end{tabular}

\subsection{The Nearest Vector Modulation}

The second approach is based on the minimum distance selection criterion, in which a distance is measured between the reference vector and basic vectors belonging to the collection of rotating voltage vectors. Another control concept, also leading to the minimisation of the number of switching, depends on choosing the one space-vector within the modulation period, which is geometrically closest to the reference vector with coordinates $v_{\alpha}^{*}$ and $v_{\beta}^{*}$. Theoretically, the number of required distances depends on the regulation range of the output phase voltage and takes the maximum value equal to 49 (48 active vectors and one zero vector). Since the following minimum value is needed

$$
r_{k}=\sqrt{\left(v_{\alpha}^{*}-v_{\alpha k}\right)^{2}+\left(v_{\beta}^{*}-v_{\beta k}\right)^{2}}
$$

in the decision process, finally another expression can be chosen

$$
g_{k}=\left(v_{\alpha}^{*}-v_{\alpha k}\right) \cdot\left(v_{\alpha}^{*}-v_{\alpha k}\right)+\left(v_{\beta}^{*}-v_{\beta k}\right) \cdot\left(v_{\beta}^{*}-v_{\beta k}\right)
$$

where

$k$-the switch state index, form 1 to 49 ,

$g_{k}$ - the proposed distance function,

$v_{\alpha k}$-vector $\alpha$ coordinate for $k$ switch state,

$v_{\beta k}-$ vector $\beta$ coordinate for $k$ switch state.

The new proposed expression contains no square root operation. Further optimisation of the algorithm may consist of taking into account the redundancy of certain switch states. The redundancy, in this case, means that the same voltage vector can be assigned to at least two switch states. In this paper, this aspect is omitted in further discussion. The algorithm calculations should be performed quite frequently to maintain best output voltage quality as possible. In order to counteract the appearance of undesirable effects associated with the so-called a short impulse, attention should be paid to the commutation capabilities of the used bi-directional switch. The commutation process should be appropriately performed according to the dynamic properties of the switch included in the datasheet. This issue is more important in medium and high power application characterised by the large currents values. Overvoltage across the switch can damage it. The proposed solution is able to be discussed for the nominal frequencies $(50 \mathrm{~Hz}$ or $60 \mathrm{~Hz}$ ) but is promising for higher frequencies used in gas turbines, ultrasounds, and high-speed drives. Such applications require modern transistors based on $\mathrm{GaN}$ or $\mathrm{SiC}$ technology. The time of the commutation 
process is much less compared to the IGBT switch counterparts. That feature has critical importance for NVM modulation, wherein the short impulse problem can appear. This aspect in the algorithm can be limited to the adoption of a specific frequency of the algorithm's call or using the hysteresis mechanisms in the sequence selection process. The quality of the proposed modulation method can be assessed using the error rate defined as follows

$$
\varepsilon_{\mathrm{RMS}}=\sqrt{\frac{1}{T_{50 \mathrm{~Hz}}} \cdot \int_{0}^{T_{50 \mathrm{~Hz}}}\left(\frac{v_{\mathrm{a}}^{*}-v_{\mathrm{a}}}{v_{\mathrm{a}}^{*}}\right)^{2} \mathrm{~d} t}
$$

The results are presented in Figure 12. The shown waveform contains four local optimum $q$ values, which correspond to the optimal multipulse operation.

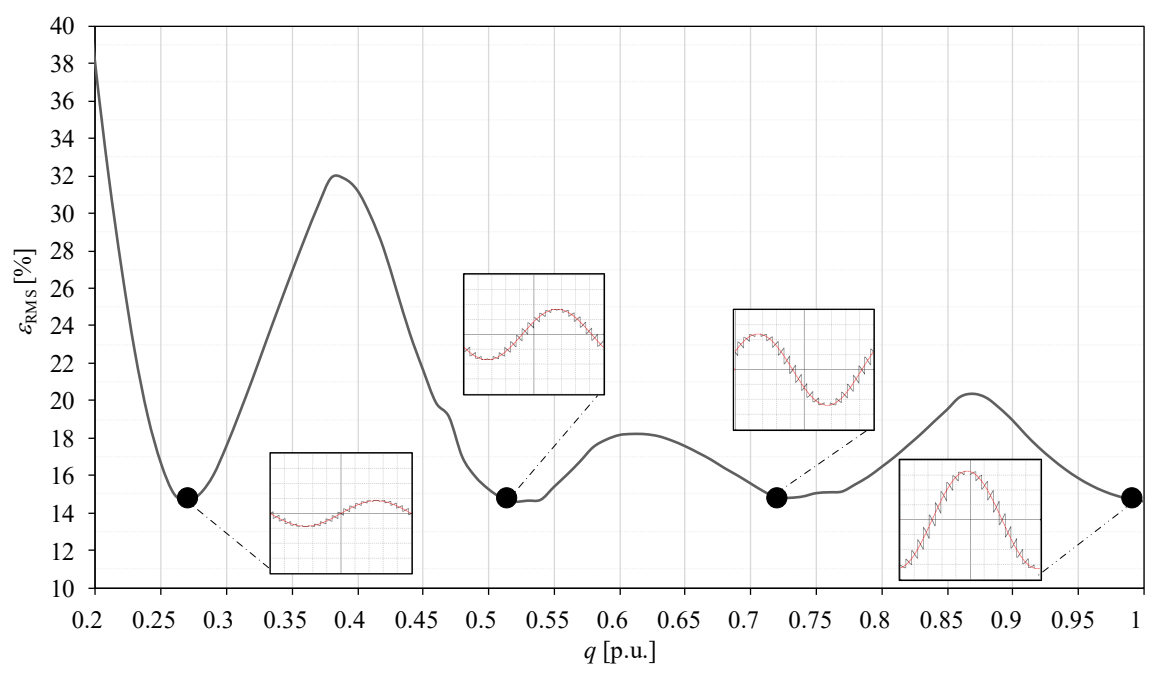

Figure 12. An error rate, defined by (21), for proposed NVM method: $n_{\mathrm{AB} 1}=n_{\mathrm{AB} 2}=209 / 209$, $n_{\mathrm{AB} 3}=571 / 209, k_{f}=1 / 12$.

\section{Research}

Initial simulation studies focused on selected modulation techniques. The converter MMCCR topology is new; therefore, it was necessary to develop modulation algorithms from scratch. Three types of modulation have been developed:

- SVPWM-this type of modulation belongs to the high-frequency switching technique, is characterised by good accuracy. The nearest three vector modulation has been adopted and developed for a new space-vector diagram presented in the previous section. The formulas of the PWM duty cycles can be found in the paper [26].

- PWR - this type of modulation allows for an amplitude control only in the limited range of modulation index with the number of switching is less than in the SVPWM. However, the precise amplitude control is worst in comparing with the SVPWM.

- $\quad \mathrm{NVM}-$ modulation with the minimum number of switching operations, dedicated to working in a steady state. The field of application may be inverters operating with a constant output frequency.

The results are presented in two subsections. Voltage and current waveforms for inverter operation with RL load are presented first. The next subsection is dedicated to a potential application in a system with a high-speed PMSM generator, as mentioned in the introduction.

\subsection{PWR and NVM Modulations in the MMCCR Inverter Mode of Operation}

Simulation has been performed using DLL block as a DSP platform emulator works with $50 \mu$ s step. The markings used in demonstrated figures are: $v_{\mathrm{a}}$-load phase voltage, 
$v_{\mathrm{A}}$ - grid phase voltage, $i_{\mathrm{a}, \mathrm{b}, \mathrm{c}}$-load currents, and $i_{\mathrm{A}, \mathrm{B}, \mathrm{C}}$-input currents. Two load models parameters sets are applied, which are listed in Table 6. All waveforms are presented in p.u. unit.

Table 6. $20 \mathrm{kVA} / 400 \mathrm{~V}$ load models simulation parameters.

\begin{tabular}{ccccc}
\hline & $\mathbf{R}[\mathbf{\Omega}]$ & $\mathbf{L}[\mathbf{H}]$ & $\mathbf{Z}[\mathbf{\Omega}]$ & $\mathbf{P F}$ \\
\hline model-1 & 7.75 & 0.0008 & 8.0 & 0.97 \\
model-2 & 4 & 0.0028 & 8.0 & 0.5 \\
\hline
\end{tabular}

Simulation tests for PWR modulation were carried for the model-1, which was characterised by a power factor of 0.97 . The proposed PWR modulation has been verified for both types of switches state sequence. Results for $\mathbf{S}_{\mathrm{MCn}}$ switches state sequence are shown in Figures 13 and 14, while the waveforms obtained for opposite rotation, $\mathbf{S}_{\mathrm{MC} p}$ switch state sequences, are illustrated in Figures 15 and 16.
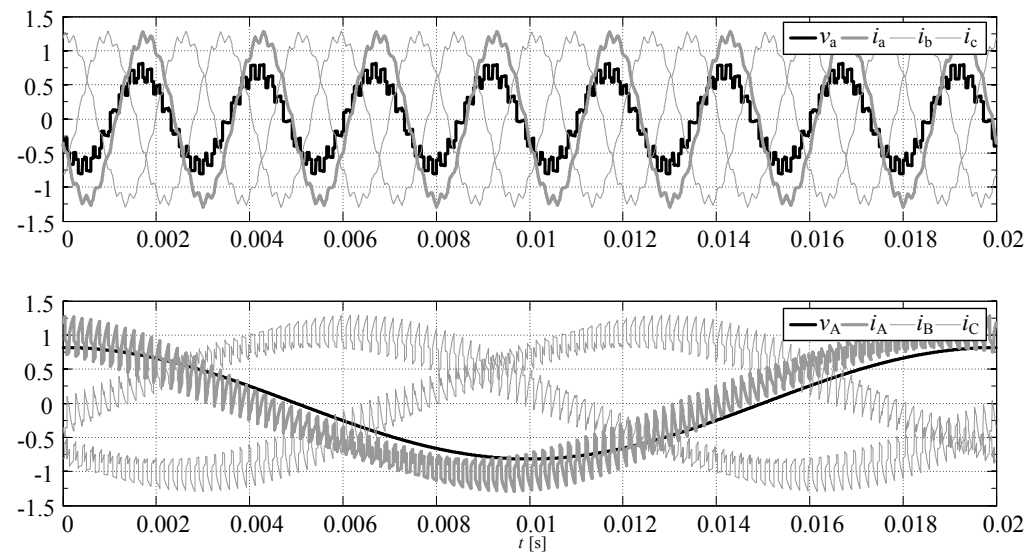

Figure 13. The waveforms of the phase voltages and currents at the output and input of the PWR controlled MMCCR for the $\mathbf{S}_{\mathrm{MCn}}$ switch state sequences: load model- $1, n_{\mathrm{AB} 1}=n_{\mathrm{AB} 2}=209 / 209$, $n_{\mathrm{AB} 3}=571 / 209, q=0.866, k_{f}=8$.
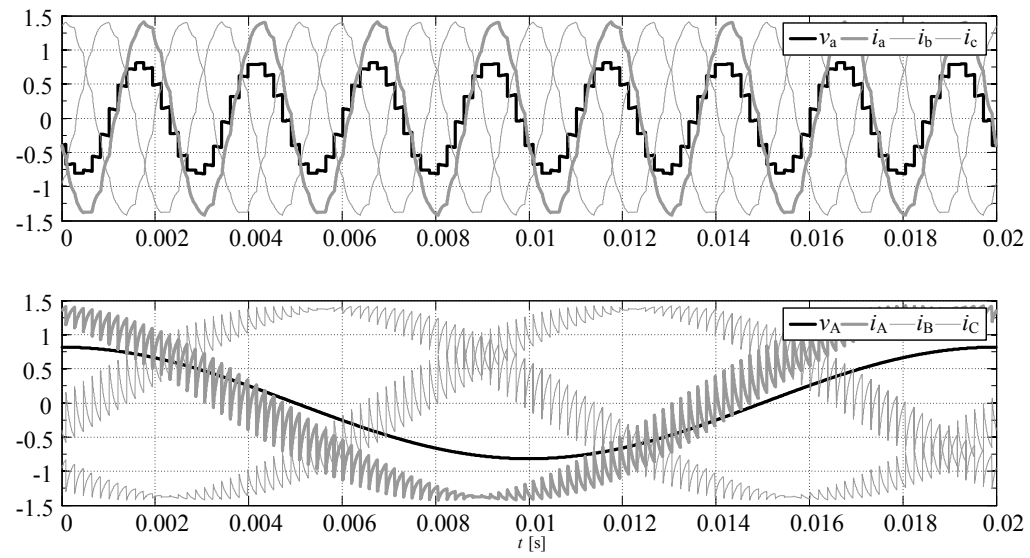

Figure 14. The waveforms of the phase voltages and currents at the output and input of the PWR controlled MMCCR for the $\mathbf{S}_{\mathrm{MCn}}$ switch state sequences: load model-1, $q=1.0, k_{f}=8$. 

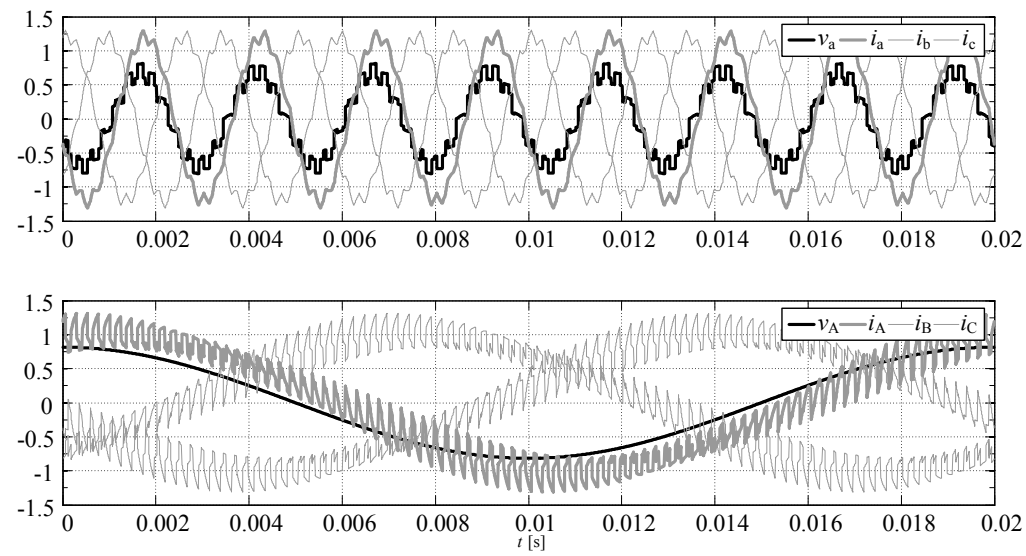

Figure 15. The waveforms of the phase voltages and currents at the output and input of the PWR controlled MMCCR for the $\mathbf{S}_{\mathrm{MC} p}$ switch state sequences: load model-1, $q=0.866, k_{f}=8$.
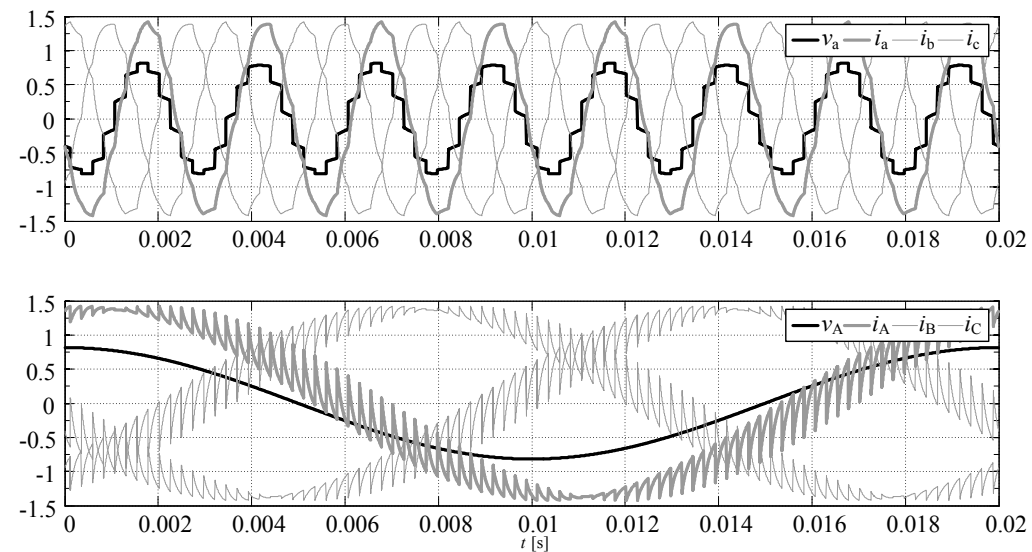

Figure 16. The waveforms of the phase voltages and currents at the output and input of the PWR controlled MMCCR for the $\mathbf{S}_{\mathrm{MC} p}$ switch state sequences: load model-1, $q=1.0, k_{f}=8$.

According to the proposed concept, for $q$ equal to unity, the output voltage is formed based only on the vectors located on the outer circle. In this case, the system works in 12 pulse mode with the optimal number of switching. Note that in all simulations, a standard input low pass filter has not been used, to demonstrate the unfiltered input current shape.

Comparison of load current Total Harmonic Distortion (THD) and average switching frequency for PWR modulation using the $\mathbf{S}_{\mathrm{MC} n}$ and $\mathbf{S}_{\mathrm{MC} p}$ switch state sequences for $k_{\mathrm{f}}=8$ is characterised in Table 7.

Table 7. Comparison of load current THD and average switching frequency for PWR modulation using the $\mathbf{S}_{\mathrm{MCn}}$ switch state sequences and $k_{\mathrm{f}}=8$.

\begin{tabular}{cccccccc}
\hline & \multicolumn{7}{c}{$\mathbf{S}_{\mathbf{M C} n}$ Switch State Type } \\
\cline { 2 - 8 }$q$ & 0.732 & 0.75 & 0.8 & 0.85 & 0.9 & 0.95 & 1 \\
\hline THD $i_{\mathrm{a}}[\%]$ & 3.15 & 3.35 & 4.8 & 5.4 & 5.2 & 4.3 & 3.1 \\
$f_{\text {switch }}[\mathrm{Hz}]$ & 1350 & 3125 & 3125 & 3125 & 3125 & 3125 & 450 \\
\hline & \multicolumn{7}{c}{$\mathbf{S}_{\mathbf{M C} p}$ Switch State Type } \\
\cline { 2 - 8 } & 0.732 & 0.75 & 0.8 & 0.85 & 0.9 & 0.95 & 1 \\
\hline THD $i_{\mathrm{a}}[\%]$ & 4.15 & 4.6 & 6.2 & 7.0 & 6.5 & 5.5 & 4.1 \\
$f_{\text {switch }}[\mathrm{Hz}]$ & 1050 & 2450 & 2450 & 2450 & 2450 & 2450 & 350 \\
\hline
\end{tabular}

As can be deduced low switching frequency MMCCR operation is achieved for voltage $q$ equal to the radius shown in Figure 10. An important feature of the matrix topology 
is the ability to the regulation of input angle, defined as displacement between the input current and grid voltage. The range of an angle regulation relies on the load parameters. In a simple way, the desired input angle can be selected using the $\mathbf{S}_{\mathrm{MCn}}$ or $\mathbf{S}_{\mathrm{MC} p}$ switch state sequences. The result of the rapid change of the switch state sequence for model-2 parameters is shown in Figure 17, in which an input angle $\phi$ is approximately equal to $\pi / 3$. Note that the proposed PWR method is elaborated only for a limited range.

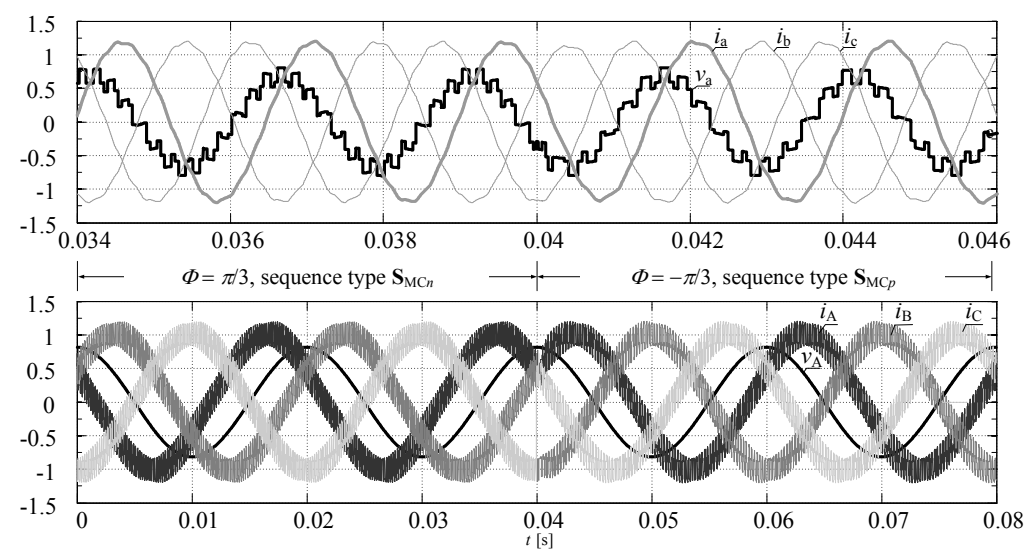

Figure 17. The zoom of the rapid change of switch sequence type for PWR modulation and load model-2, $q=0.866$, and $k_{f}=8$.

The proposed PWR modulation is not an accurate voltage synthesis method. Formula (16) calculates the proportion only in an estimated way, assuming that the voltages are constant in the modulation period.

A simulation has been performed in which the Root Mean Square (RMS) value and THD of the load current have been calculated. Figure 18 shows maximal magnetic flux values referred to the case of the $50 \mathrm{~Hz}$ output waveform generation in function of voltage transfer ratio $q$ and output frequency ratio $k_{f}$. On the basis of the collected data, it was confirmed that the magnetic flux value is linearly dependent on the output frequency. On the other hand, a smaller flux allows for a smaller design of the coupled reactor circuit. Therefore, the proposed solution will work better in applications with a higher fundamental frequency.

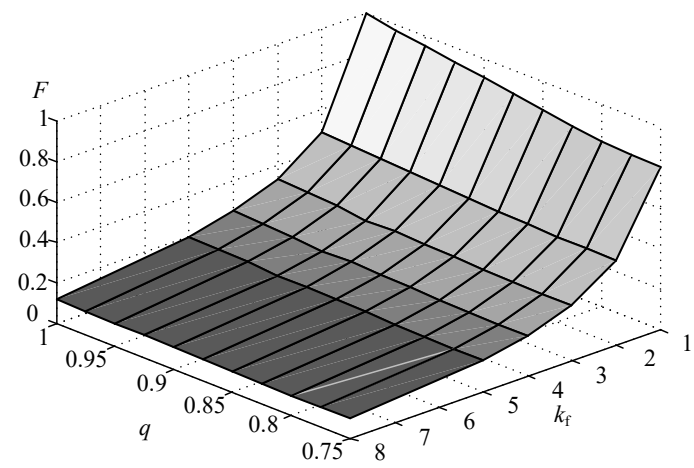

Figure 18. The maximal relative magnetic flux $F$ in $\mathrm{PS}_{3}$ coupled reactor in function of voltage transfer ratio $q$ and output frequency ratio $k_{f}$.

Figure 19 presents an example of current and voltage waveforms in the case of $400 \mathrm{~Hz}$ voltage generation using the NVM method. The presented fragment of the waveforms refers to the case when the output voltage amplitude is gradually increased. The results were obtained for the load model-1. 

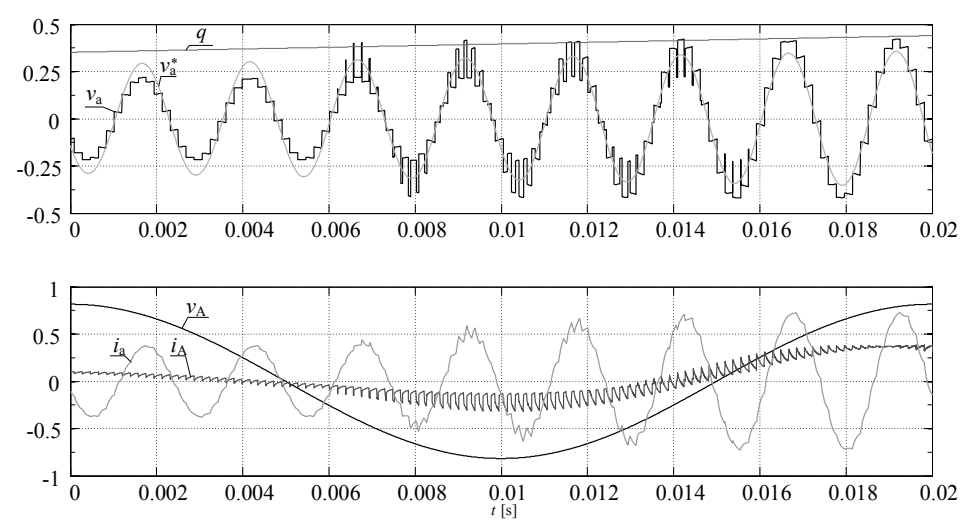

Figure 19. Example output voltage waveforms, for NVM modulation, during gradually increasing the voltage gain $q$ from 0.27 to 0.43 for $k_{f}=8$.

Figure 20a shows a comparison of THD modulation methods described in the article. Obviously, curves in the figure are not similar because they represent different approaches to low-frequency modulation. To formulate conclusions one should also consider the results presented in Figure 20b, in which the RMS load currents have been compared to the reference current.

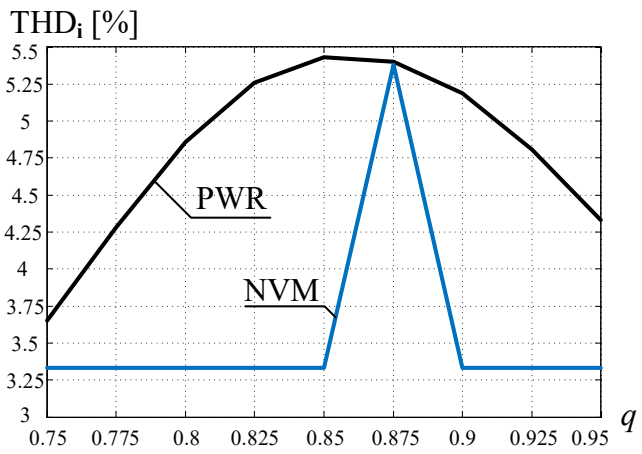

(a)

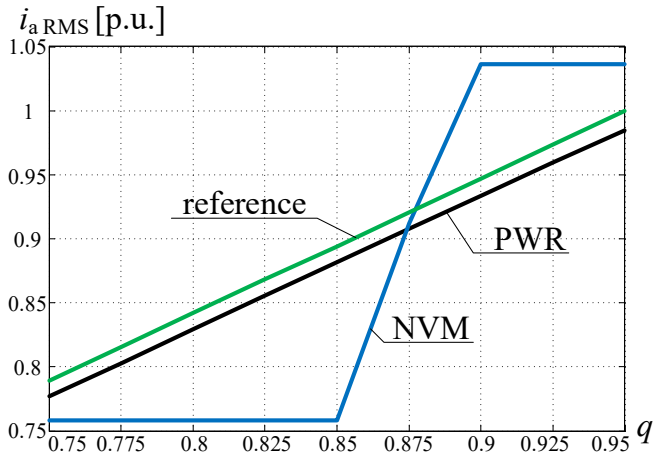

(b)

Figure 20. The comparison of the PWR and NVM modulation methods during the inverter operation: (a) the load current total harmonic distortion in the applicable range of modulation index, (b) the load current RMS value comparison of reference and proposed modulation.

\subsection{A Potential Application in a System with a High-Speed PMSM Generator}

The proposed MMCCR converter can be applied in a system with a high-speed PMSM generator. Figure 21 shows a simplified circuit for simulation tests, while the proposed control diagram is presented in Figure 22. The purpose of the simulation tests was as follows:

- comparing the converters CMC and MMCCR controlled by SVPWM modulation,

- investigating the possibility of the system control for active NVM modulation with the low-frequency switching within a steady-state operation (shown in Figure 2).

Precise amplitude control is required during generator start-up and synchronisation with the grid. The SVPWM method based on the three nearest vectors selection has been used. At this stage, simulation studies focused on the verification of the possibility of controlling the active component of the generator current, estimating the THD for selected waveforms, and determining the number of switching of power electronic switches. 


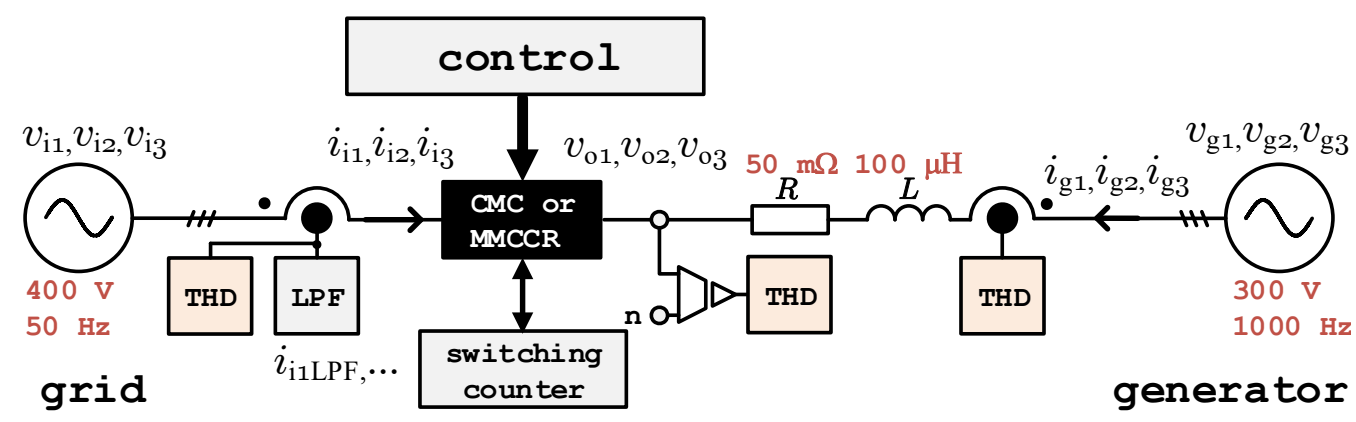

Figure 21. A potential application scheme with a high-speed PMSM generator: CMC - conventional matrix converter, MMCCR - the proposed converter, THD — calculation of the total harmonic distortion block, LPF-the low-pass filter, and " $\mathrm{n}$ "—-the star point for the phase voltage measurement.

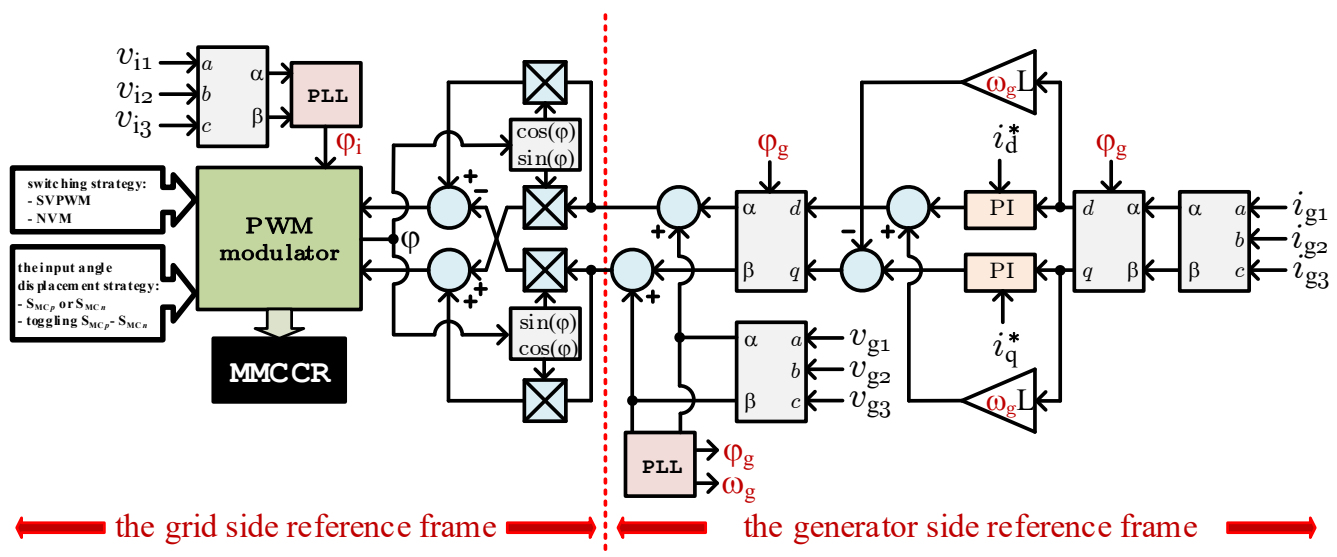

Figure 22. The proposed control scheme: PLL—phase-locked loop, MMCCR-the proposed converter, PI-standard proportional integral controller, $\varphi_{\mathrm{i}}$ - $\operatorname{grid}^{\prime} \mathrm{s}$ voltage angle, $\varphi$ - the synchronisations angle, $\varphi_{\mathrm{g}}$-generator's voltage angle, $i_{d}^{*}$ - an active reference current for generator, $i_{q}-\mathrm{a}$ reactive reference current for generator, $\omega_{\mathrm{g}}=\omega_{\mathrm{m}}$-for simplicity, mechanical pulsation is equal to electrical pulsation.

Selected results of the comparison CMC and MMCCR converters during SVPWM modulation are shown in Table 8 . All presented measurements were carried out for the modulation period equal to $10 \mu$ s and the set active current of the generator $200 \mathrm{~A}$. For the MMCCR converter, compared to the CMC topology, the THD factor of the input current and the output voltage is over 2.5 times lower, while maintaining a constant value of the modulation period. In addition, the quality of the generator current is better.

Table 8. Selected results of the comparison CMC and MMCCR converters during SVPWMmodulation.

\begin{tabular}{ccccc}
\hline Converter Type & THD $\left(\boldsymbol{i}_{\mathbf{i} 1}\right)$ & $\mathbf{T H D}\left(\boldsymbol{v}_{\mathbf{o} 1}\right)$ & $\mathbf{T H D}\left(\boldsymbol{i}_{\mathbf{g} 1}\right)$ & The Relative Number of Switching Operations \\
\hline CMC & $74 \%$ & $73 \%$ & $1.6 \%$ & $100 \%$ \\
MMCCR & $28 \%$ & $26 \%$ & $0.85 \%$ & $\simeq 50 \%$ \\
\hline
\end{tabular}

Example waveforms of currents and voltages are shown in Figure 23. The simulation performed for the step change of the reference active generator current, from 0 to 200 A (approximately $75 \mathrm{~kW}$ power) in $t=0.07 \mathrm{~s}$. As can be seen, the shape of the input current and the voltage generated by the converters have differed. The MMCCR generates a quasi multilevel voltage and the input current shape is near to the sinusoidal waveform. The input current spectrums for both converters are presented in Figure 24. 


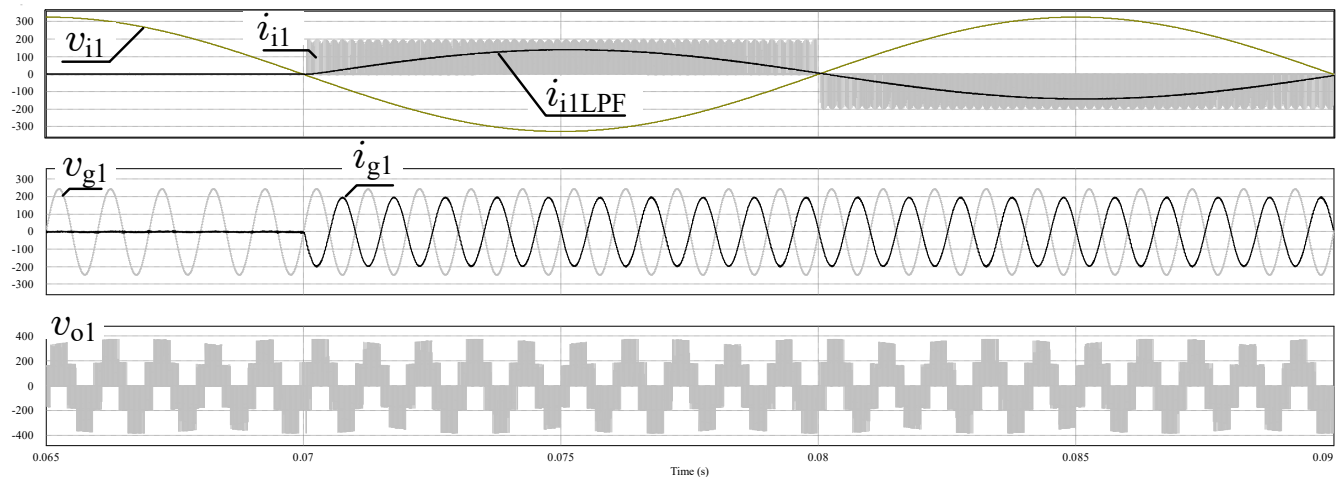

(a)

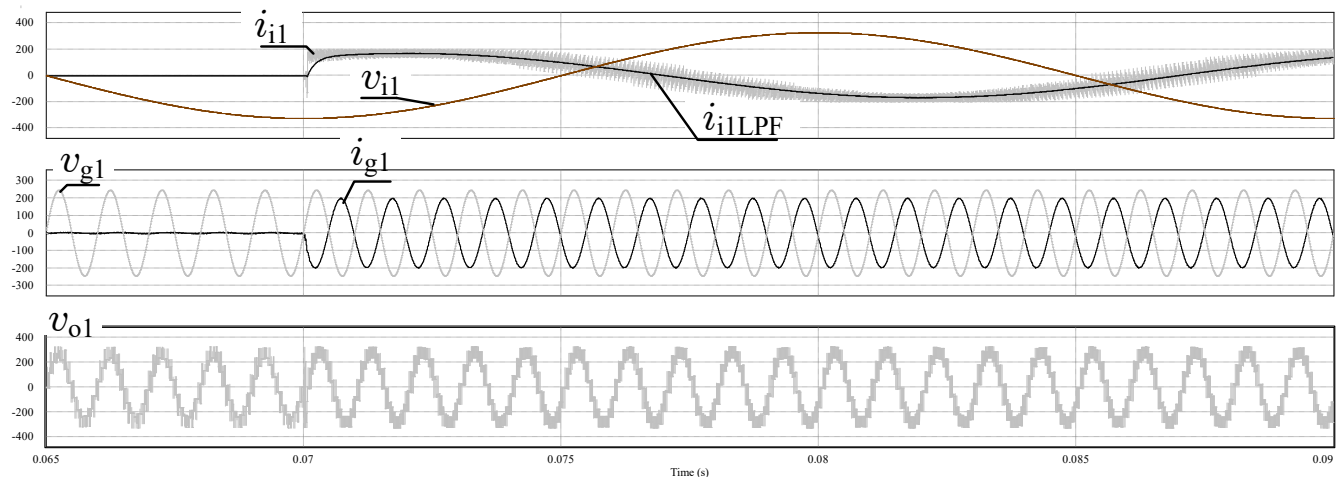

(b)

Figure 23. The step change 0-200 A of the reference active generator current in $t=0.07 \mathrm{~s}$ : (a) for CMC converter, (b) for MMCCR converter.

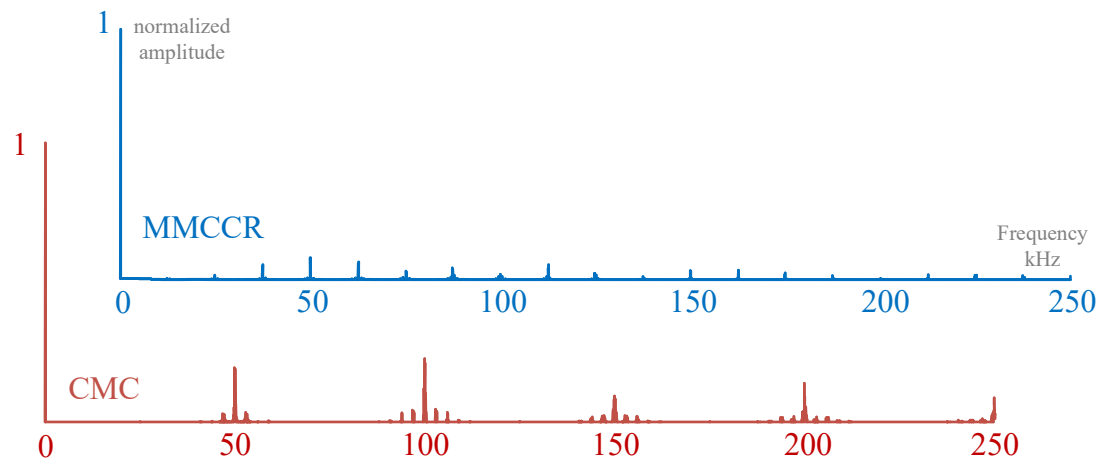

Figure 24. The input current spectrums for both converters.

The proposed MMCCR topology contains four matrix converters and three-phase shifter circuits. As mentioned in an introduction section, the power is equally divided with among these matrix converters. Example PS currents $i_{\mathrm{PS} 1}, i_{\mathrm{PS} 2}$, and $i_{\mathrm{PS} 3}$ are shown in Figure 25.

In steady-state it is possible to change the control strategy. The SVPWM method can be replaced by NVM modulation, which is characterised by a much lower operating frequency of power electronic switches. However, new PI controllers settings should be selected in this case to keep the staircase character of the generated voltage. An obtained example of converter's voltage and other waveforms, during an active NVM modulation, is shown in Figures 26 and 27. 


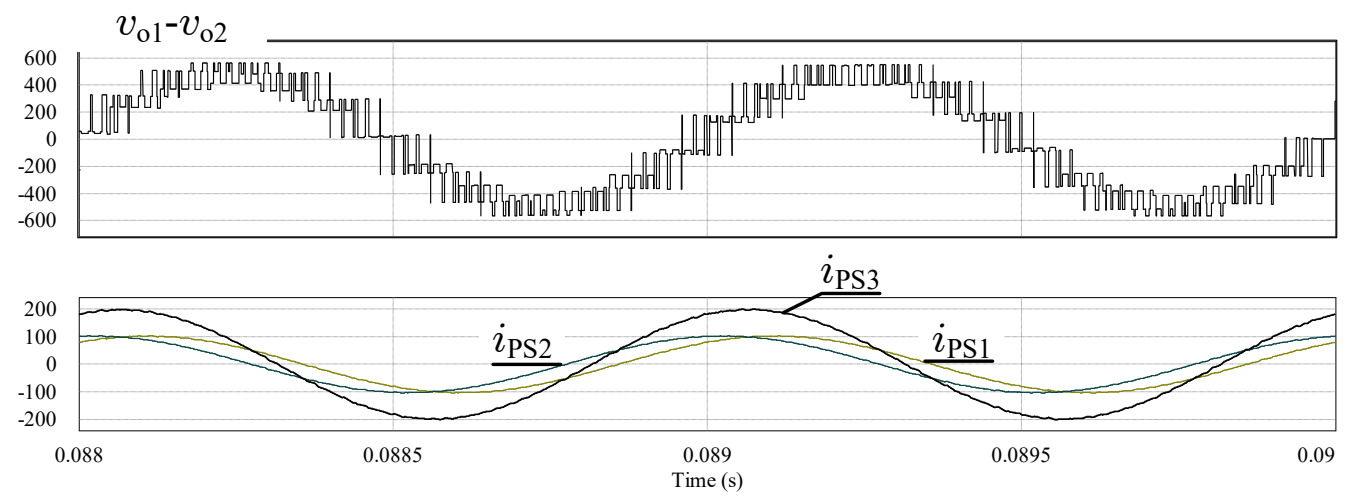

Figure 25. Converter's line-to-line output (correspond to Figure 21) voltage and the current sharing among the PS shown in Figure 6-SVPWM modulation.

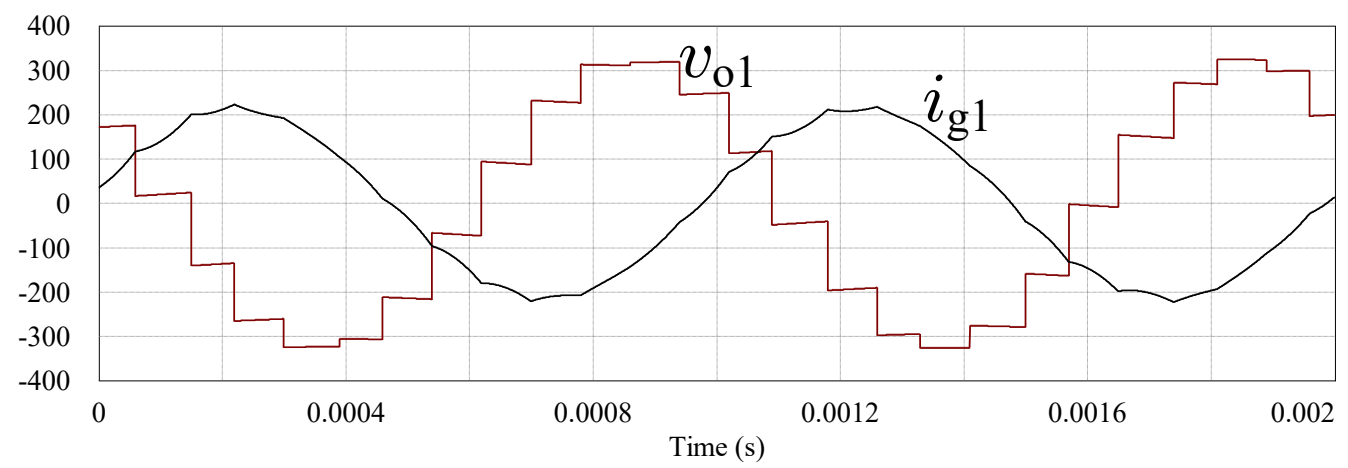

Figure 26. MMCCR converter' output voltage $v_{\mathrm{o} 1}$ and the generator current $i_{\mathrm{g} 1}$ for NVM modulation: $\operatorname{THD}\left(i_{\mathrm{g} 1}\right)=3.5 \%$ and $\operatorname{THD}\left(v_{\mathrm{o} 1}\right)=16 \%$.

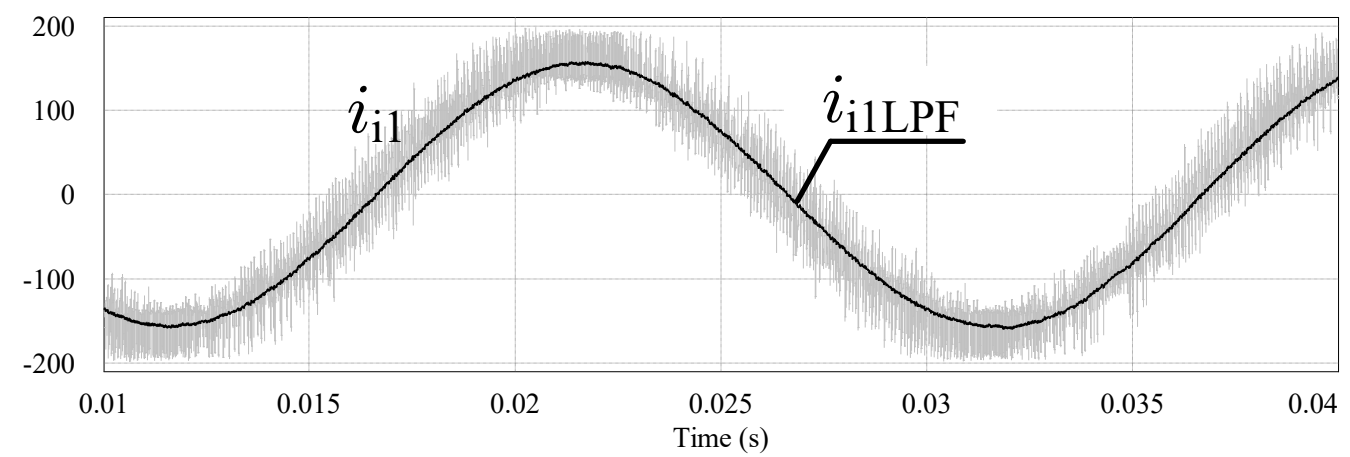

Figure 27. An input current $i_{\mathrm{i} 1}$ and its filtered waveform $i_{\mathrm{i} 1 \mathrm{LPF}}$ for NVM modulation: $\operatorname{THD}\left(i_{\mathrm{i} 1}\right)=26 \%$.

\section{Conclusions}

This article studies nature and presents conceptual research and discusses the different Pulse Width Modulation (PWM) strategies for operating, with a low-switching frequency for the proposed topology. It shows how the unconventional combination of CMC modules and CR could improve the quality of energy conversion. The paper also presents how this solution may be specifically appropriate for the high power systems, that are supplied by the high AC frequency sources, such as the high-speed generators or airport terminals' supply of $400 \mathrm{~Hz}$.

The main features of the proposed approach are as follows:

- The use of coupled reactors allows the generation of voltages with staircase character (see Figure 26) with relatively low switching frequency operation, which depends on the value of the reference voltage. However, the staircase-type waveforms of the load voltages are obtained only for maximum voltage gain (for both NVM and 
PWR modulations) or for the certain values of the NVM modulation index, as shown in Figure 12.

- Increasing the number of CMC devices allows for the achievement of the voltage gain close to unity. For CMC, the voltage gain is no greater than 0.866 , while for the proposed topology, the generated maximum amplitude is $11 \%$ greater. However, four PS circuits are required. Therefore, and also due to the volumes of coupled reactors, the application of the discussed system is the most rational in the case of high frequencies at the output and/or output of the CMC, e.g., in gas turbines.

- The content of higher harmonics in the voltage, generated using PWR and NVM algorithms, is not linearly dependent on the reference load voltage value, this can make application of the proposed solution problematic in a full range of load voltage amplitude changes. Therefore, the proposed type of amplitude control should be used and optimised preferably in systems with a fixed output frequency. Only the SVPWM method, based on the rotating vectors, can be utilised in a full range of the modulation index.

- In comparison with high-frequency methods such as PWM, both PWR regulation and NVM modulation are not precise methods generating output voltages. Therefore, the proposed solution will not find application even in electric drive with high requirements for dynamics. However, it can be assumed that apart from reducing switching losses, the EMI level will also decrease. Due to these properties, the presented modulation methods can be applied in converters for high-speed generators/motors and also the onboard power supply.

In the case of MMCCR control with NVM modulation, it is possible to achieve a reasonable compromise between low THD value and relatively low frequency of power switches. However, as shown in Figure 20, in case of NVM modulation, it is difficult to control the output current/voltage with reference amplitude changes. Special switchable algorithms are required. Much better control possibilities, albeit at the cost of increasing THD and about 2 times the switching frequency, can be achieved when implementing the PWR algorithm. A further increase in the precision of the generation and control range of the output current/voltage is possible by means of SVPWM modulation for two rotating spatial vectors. This results in higher switching frequency and control calculation problems for CMC systems, in particular for this 12-pulse MMCCR. In order to reduce the importance of these problems and the related requirements on the capabilities of processor controllers, the authors initially propose to use the barycentric coordinate method [19], which unifies and simplifies calculations.

The research of this method in relation to the MMCCR system, including the hybrid method [25], allowing to minimize the frequency of connections in the converter at fixed points will be presented in the next paper. This study article does not in any way pretend to present the full spectrum of problems associated with MMCCR systems. Its main objective was only to present the possibilities and basic properties of equalising typical CMC modules with chokes coupled with overall power of no more than about $30 \%$ of the rated power of the whole system. The above objective also includes a general discussion of dedicated control algorithms. Considering the generality and the material's size, only the most important theoretical issues verified by simulation are presented. Experimental research on specific cases will be the subject of further publications in the near future.

Author Contributions: Conceptualisation: P.S. and N.S., investigation and simulation: P.S. and J.L., validation, formal analysis: A.U., final editing: P.S. and E.R.-C. All authors have read and agreed to the published version of the manuscript.

Funding: This work was supported by the $\operatorname{LINTE}^{\wedge} 2$ Laboratory, Gdansk University of Technology. It was also supported by ITMO University Saint Petersburg, Russian Federation.

Conflicts of Interest: The authors declare no conflict of interest. 


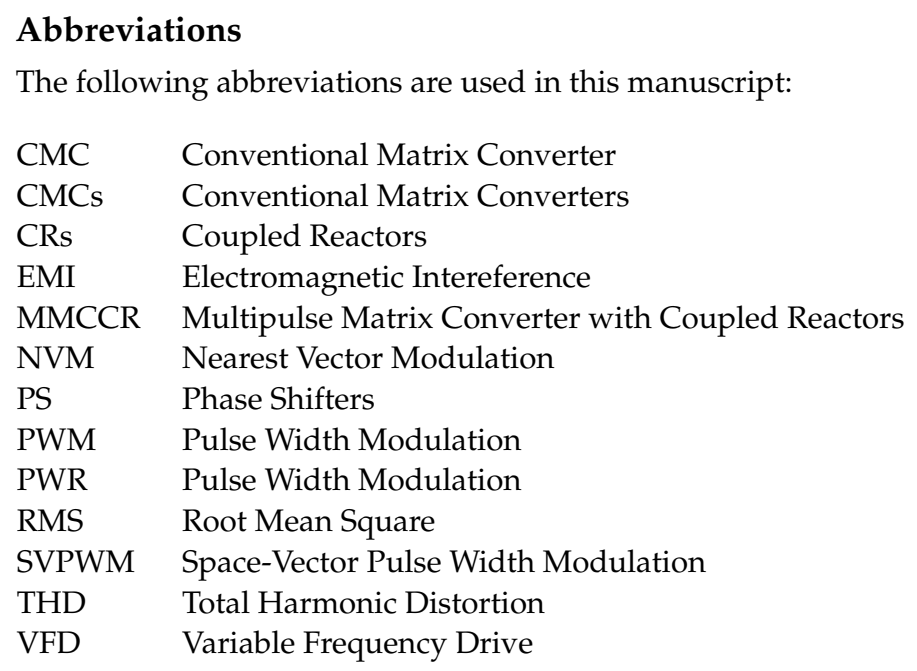

Appendix A

Table A1. The $\mathbf{S}_{\mathrm{MCn}}$ Switch States.

\begin{tabular}{ccccc}
\hline & $S_{\mathrm{A} 1} \ldots S_{\mathrm{C} 3}$ & $S_{\mathrm{A} 4} . . . S_{\mathrm{C} 6}$ & $S_{\mathrm{A} 7} \ldots S_{\mathrm{C} 9}$ & $S_{\mathrm{A} 10 . . S_{\mathrm{C} 12}}$ \\
\hline V0 & $001-100-010$ & $001-100-010$ & $001-100-010$ & $001-100-010$ \\
V1 & $001-100-010$ & $001-100-010$ & $001-100-010$ & $010-001-100$ \\
V2 & $001-100-010$ & $001-100-010$ & $001-100-010$ & $100-010-001$ \\
V3 & $001-100-010$ & $001-100-010$ & $010-001-100$ & $001-100-010$ \\
V4 & $001-100-010$ & $001-100-010$ & $010-001-100$ & $010-001-100$ \\
V5 & $001-100-010$ & $001-100-010$ & $010-001-100$ & $100-010-001$ \\
V6 & $001-100-010$ & $001-100-010$ & $100-010-001$ & $001-100-010$ \\
V7 & $001-100-010$ & $001-100-010$ & $100-010-001$ & $010-001-100$ \\
V8 & $001-100-010$ & $001-100-010$ & $100-010-001$ & $100-010-001$ \\
V9 & $001-100-010$ & $010-001-100$ & $001-100-010$ & $001-100-010$ \\
V10 & $001-100-010$ & $010-001-100$ & $001-100-010$ & $010-001-100$ \\
V11 & $001-100-010$ & $010-001-100$ & $001-100-010$ & $100-010-001$ \\
V12 & $001-100-010$ & $010-001-100$ & $010-001-100$ & $001-100-010$ \\
V13 & $001-100-010$ & $010-001-100$ & $010-001-100$ & $010-001-100$ \\
V14 & $001-100-010$ & $010-001-100$ & $010-001-100$ & $100-010-001$ \\
V15 & $001-100-010$ & $010-001-100$ & $100-010-001$ & $001-100-010$ \\
V16 & $001-100-010$ & $010-001-100$ & $100-010-001$ & $010-001-100$ \\
V17 & $001-100-010$ & $010-001-100$ & $100-010-001$ & $100-010-001$ \\
V18 & $001-100-010$ & $100-010-001$ & $001-100-010$ & $001-100-010$ \\
V19 & $001-100-010$ & $100-010-001$ & $001-100-010$ & $010-001-100$ \\
V20 & $001-100-010$ & $100-010-001$ & $001-100-010$ & $100-010-001$ \\
V21 & $001-100-010$ & $100-010-001$ & $010-001-100$ & $001-100-010$ \\
V22 & $001-100-010$ & $100-010-001$ & $010-001-100$ & $010-001-100$ \\
V23 & $001-100-010$ & $100-010-001$ & $010-001-100$ & $100-010-001$ \\
V24 & $001-100-010$ & $100-010-001$ & $100-010-001$ & $001-100-010$ \\
V25 & $001-100-010$ & $100-010-001$ & $100-010-001$ & $010-001-100$ \\
V26 & $001-100-010$ & $100-010-001$ & $100-010-001$ & $100-010-001$ \\
V27 & $010-001-100$ & $001-100-010$ & $001-100-010$ & $001-100-010$ \\
V28 & $010-001-100$ & $001-100-010$ & $001-100-010$ & $010-001-100$ \\
V29 & $010-001-100$ & $001-100-010$ & $001-100-010$ & $100-010-001$ \\
\hline & & & & \\
\hline
\end{tabular}


Table A1. Cont.

\begin{tabular}{|c|c|c|c|c|}
\hline & $S_{\mathrm{A} 1} \ldots S_{\mathrm{C} 3}$ & $S_{\mathrm{A} 4} \ldots S_{\mathrm{C} 6}$ & $S_{\mathrm{A} 7} \ldots S_{\mathrm{C} 9}$ & $S_{\mathrm{A} 10} \ldots S_{\mathrm{C} 12}$ \\
\hline V30 & 010-001-100 & 001-100-010 & 010-001-100 & 001-100-010 \\
\hline V31 & 010-001-100 & 001-100-010 & 010-001-100 & 010-001-100 \\
\hline V32 & 010-001-100 & 001-100-010 & 010-001-100 & $100-010-001$ \\
\hline V33 & 010-001-100 & 001-100-010 & 100-010-001 & 001-100-010 \\
\hline V34 & 010-001-100 & 001-100-010 & 100-010-001 & 010-001-100 \\
\hline V35 & 010-001-100 & 001-100-010 & 100-010-001 & $100-010-001$ \\
\hline V36 & 010-001-100 & 010-001-100 & 001-100-010 & 001-100-010 \\
\hline V37 & 010-001-100 & 010-001-100 & 001-100-010 & 010-001-100 \\
\hline V38 & 010-001-100 & 010-001-100 & 001-100-010 & $100-010-001$ \\
\hline V39 & 010-001-100 & 010-001-100 & 010-001-100 & 001-100-010 \\
\hline V40 & 010-001-100 & 010-001-100 & 010-001-100 & 010-001-100 \\
\hline V41 & 010-001-100 & 010-001-100 & 010-001-100 & $100-010-001$ \\
\hline V42 & 010-001-100 & 010-001-100 & 100-010-001 & 001-100-010 \\
\hline V43 & 010-001-100 & 010-001-100 & 100-010-001 & 010-001-100 \\
\hline V44 & 010-001-100 & 010-001-100 & 100-010-001 & $100-010-001$ \\
\hline V45 & 010-001-100 & $100-010-001$ & 001-100-010 & 001-100-010 \\
\hline V46 & 010-001-100 & $100-010-001$ & 001-100-010 & 010-001-100 \\
\hline V47 & 010-001-100 & $100-010-001$ & 001-100-010 & $100-010-001$ \\
\hline V48 & 010-001-100 & $100-010-001$ & 010-001-100 & 001-100-010 \\
\hline V49 & 010-001-100 & $100-010-001$ & 010-001-100 & 010-001-100 \\
\hline V50 & 010-001-100 & $100-010-001$ & 010-001-100 & $100-010-001$ \\
\hline V51 & 010-001-100 & $100-010-001$ & 100-010-001 & 001-100-010 \\
\hline V52 & 010-001-100 & $100-010-001$ & $100-010-001$ & 010-001-100 \\
\hline V53 & 010-001-100 & $100-010-001$ & $100-010-001$ & $100-010-001$ \\
\hline V54 & $100-010-001$ & 001-100-010 & 001-100-010 & 001-100-010 \\
\hline V55 & $100-010-001$ & 001-100-010 & 001-100-010 & 010-001-100 \\
\hline V56 & $100-010-001$ & 001-100-010 & 001-100-010 & $100-010-001$ \\
\hline V57 & $100-010-001$ & 001-100-010 & 010-001-100 & 001-100-010 \\
\hline V58 & $100-010-001$ & 001-100-010 & 010-001-100 & 010-001-100 \\
\hline V59 & $100-010-001$ & 001-100-010 & 010-001-100 & $100-010-001$ \\
\hline V60 & $100-010-001$ & 001-100-010 & 100-010-001 & 001-100-010 \\
\hline V61 & $100-010-001$ & 001-100-010 & 100-010-001 & 010-001-100 \\
\hline V62 & $100-010-001$ & 001-100-010 & 100-010-001 & $100-010-001$ \\
\hline V63 & 100-010-001 & 010-001-100 & 001-100-010 & 001-100-010 \\
\hline V64 & 100-010-001 & 010-001-100 & 001-100-010 & 010-001-100 \\
\hline V65 & 100-010-001 & 010-001-100 & 001-100-010 & $100-010-001$ \\
\hline V66 & 100-010-001 & 010-001-100 & 010-001-100 & 001-100-010 \\
\hline V67 & $100-010-001$ & 010-001-100 & 010-001-100 & 010-001-100 \\
\hline V68 & $100-010-001$ & 010-001-100 & 010-001-100 & $100-010-001$ \\
\hline V69 & $100-010-001$ & 010-001-100 & $100-010-001$ & 001-100-010 \\
\hline V70 & $100-010-001$ & 010-001-100 & 100-010-001 & 010-001-100 \\
\hline V71 & $100-010-001$ & 010-001-100 & $100-010-001$ & $100-010-001$ \\
\hline V72 & 100-010-001 & 100-010-001 & 001-100-010 & 001-100-010 \\
\hline V73 & $100-010-001$ & $100-010-001$ & 001-100-010 & 010-001-100 \\
\hline V74 & $100-010-001$ & $100-010-001$ & 001-100-010 & $100-010-001$ \\
\hline V75 & $100-010-001$ & $100-010-001$ & 010-001-100 & 001-100-010 \\
\hline V76 & $100-010-001$ & $100-010-001$ & 010-001-100 & 010-001-100 \\
\hline V77 & $100-010-001$ & $100-010-001$ & 010-001-100 & 100-010-001 \\
\hline V78 & $100-010-001$ & $100-010-001$ & $100-010-001$ & 001-100-010 \\
\hline V79 & $100-010-001$ & $100-010-001$ & 100-010-001 & 010-001-100 \\
\hline V80 & $100-010-001$ & $100-010-001$ & 100-010-001 & 100-010-001 \\
\hline
\end{tabular}


Table A2. The $\mathbf{S}_{\mathrm{MC} p}$ Switch States.

\begin{tabular}{|c|c|c|c|c|}
\hline & $s_{\mathrm{A} 1} \ldots s_{\mathrm{C} 3}$ & $S_{\mathrm{A} 4} \ldots s_{\mathrm{C} 6}$ & $S_{\mathrm{A} 7} \ldots S_{\mathrm{C} 9}$ & $S_{\mathrm{A} 10} \ldots S_{\mathrm{C} 12}$ \\
\hline V0 & 001-010-100 & 001-010-100 & 001-010-100 & 001-010-100 \\
\hline V1 & 001-010-100 & 001-010-100 & 001-010-100 & 010-100-001 \\
\hline $\mathrm{V} 2$ & 001-010-100 & 001-010-100 & 001-010-100 & $100-001-010$ \\
\hline V3 & 001-010-100 & 001-010-100 & 010-100-001 & 001-010-100 \\
\hline V4 & 001-010-100 & 001-010-100 & 010-100-001 & 010-100-001 \\
\hline V5 & 001-010-100 & 001-010-100 & 010-100-001 & $100-001-010$ \\
\hline V6 & 001-010-100 & 001-010-100 & $100-001-010$ & 001-010-100 \\
\hline V7 & 001-010-100 & 001-010-100 & $100-001-010$ & 010-100-001 \\
\hline V8 & 001-010-100 & 001-010-100 & $100-001-010$ & $100-001-010$ \\
\hline V9 & 001-010-100 & 010-100-001 & 001-010-100 & 001-010-100 \\
\hline V10 & 001-010-100 & 010-100-001 & 001-010-100 & 010-100-001 \\
\hline V11 & 001-010-100 & 010-100-001 & 001-010-100 & $100-001-010$ \\
\hline V12 & 001-010-100 & 010-100-001 & 010-100-001 & 001-010-100 \\
\hline V13 & 001-010-100 & 010-100-001 & 010-100-001 & 010-100-001 \\
\hline V14 & 001-010-100 & 010-100-001 & 010-100-001 & $100-001-010$ \\
\hline V15 & 001-010-100 & 010-100-001 & $100-001-010$ & 001-010-100 \\
\hline V16 & 001-010-100 & 010-100-001 & $100-001-010$ & 010-100-001 \\
\hline V17 & 001-010-100 & 010-100-001 & $100-001-010$ & $100-001-010$ \\
\hline V18 & 001-010-100 & $100-001-010$ & 001-010-100 & 001-010-100 \\
\hline V19 & 001-010-100 & $100-001-010$ & 001-010-100 & 010-100-001 \\
\hline V20 & 001-010-100 & $100-001-010$ & 001-010-100 & $100-001-010$ \\
\hline V21 & 001-010-100 & $100-001-010$ & 010-100-001 & 001-010-100 \\
\hline V22 & 001-010-100 & $100-001-010$ & 010-100-001 & 010-100-001 \\
\hline V23 & 001-010-100 & $100-001-010$ & 010-100-001 & $100-001-010$ \\
\hline V24 & 001-010-100 & $100-001-010$ & $100-001-010$ & 001-010-100 \\
\hline V25 & 001-010-100 & $100-001-010$ & $100-001-010$ & 010-100-001 \\
\hline V26 & 001-010-100 & $100-001-010$ & $100-001-010$ & $100-001-010$ \\
\hline V27 & 010-100-001 & 001-010-100 & 001-010-100 & 001-010-100 \\
\hline V28 & 010-100-001 & 001-010-100 & 001-010-100 & 010-100-001 \\
\hline V29 & 010-100-001 & 001-010-100 & 001-010-100 & $100-001-010$ \\
\hline V30 & 010-100-001 & 001-010-100 & 010-100-001 & 001-010-100 \\
\hline V31 & 010-100-001 & 001-010-100 & 010-100-001 & 010-100-001 \\
\hline V32 & 010-100-001 & 001-010-100 & 010-100-001 & $100-001-010$ \\
\hline V33 & 010-100-001 & 001-010-100 & $100-001-010$ & 001-010-100 \\
\hline V34 & 010-100-001 & 001-010-100 & $100-001-010$ & 010-100-001 \\
\hline V35 & 010-100-001 & 001-010-100 & $100-001-010$ & $100-001-010$ \\
\hline V36 & 010-100-001 & 010-100-001 & 001-010-100 & 001-010-100 \\
\hline V37 & 010-100-001 & 010-100-001 & 001-010-100 & 010-100-001 \\
\hline V38 & 010-100-001 & 010-100-001 & 001-010-100 & $100-001-010$ \\
\hline V39 & 010-100-001 & 010-100-001 & 010-100-001 & 001-010-100 \\
\hline V40 & 010-100-001 & 010-100-001 & 010-100-001 & 010-100-001 \\
\hline V41 & 010-100-001 & 010-100-001 & 010-100-001 & $100-001-010$ \\
\hline V42 & 010-100-001 & 010-100-001 & $100-001-010$ & 001-010-100 \\
\hline V43 & 010-100-001 & 010-100-001 & $100-001-010$ & 010-100-001 \\
\hline V44 & 010-100-001 & 010-100-001 & $100-001-010$ & $100-001-010$ \\
\hline V45 & 010-100-001 & $100-001-010$ & 001-010-100 & 001-010-100 \\
\hline V46 & 010-100-001 & $100-001-010$ & 001-010-100 & 010-100-001 \\
\hline V47 & 010-100-001 & $100-001-010$ & 001-010-100 & $100-001-010$ \\
\hline V48 & 010-100-001 & $100-001-010$ & 010-100-001 & 001-010-100 \\
\hline V49 & 010-100-001 & $100-001-010$ & 010-100-001 & 010-100-001 \\
\hline V50 & 010-100-001 & $100-001-010$ & 010-100-001 & $100-001-010$ \\
\hline
\end{tabular}


Table A2. Cont.

\begin{tabular}{|c|c|c|c|c|}
\hline & $s_{\mathrm{A} 1} \ldots s_{\mathrm{C} 3}$ & $S_{\mathrm{A} 4} \ldots s_{\mathrm{C} 6}$ & $S_{\mathrm{A} 7} \ldots S_{\mathrm{C} 9}$ & $S_{\mathrm{A} 10} \ldots S_{\mathrm{C} 12}$ \\
\hline V51 & 010-100-001 & $100-001-010$ & $100-001-010$ & 001-010-100 \\
\hline V52 & 010-100-001 & $100-001-010$ & $100-001-010$ & 010-100-001 \\
\hline V53 & 010-100-001 & $100-001-010$ & $100-001-010$ & $100-001-010$ \\
\hline V54 & $100-001-010$ & 001-010-100 & 001-010-100 & 001-010-100 \\
\hline V55 & $100-001-010$ & 001-010-100 & 001-010-100 & 010-100-001 \\
\hline V56 & $100-001-010$ & 001-010-100 & 001-010-100 & $100-001-010$ \\
\hline V57 & $100-001-010$ & 001-010-100 & 010-100-001 & 001-010-100 \\
\hline V58 & $100-001-010$ & 001-010-100 & 010-100-001 & 010-100-001 \\
\hline V59 & $100-001-010$ & 001-010-100 & 010-100-001 & $100-001-010$ \\
\hline V60 & $100-001-010$ & 001-010-100 & $100-001-010$ & 001-010-100 \\
\hline V61 & $100-001-010$ & 001-010-100 & 100-001-010 & 010-100-001 \\
\hline V62 & $100-001-010$ & 001-010-100 & $100-001-010$ & $100-001-010$ \\
\hline V63 & $100-001-010$ & 010-100-001 & 001-010-100 & 001-010-100 \\
\hline V64 & $100-001-010$ & 010-100-001 & 001-010-100 & 010-100-001 \\
\hline V65 & $100-001-010$ & 010-100-001 & 001-010-100 & $100-001-010$ \\
\hline V66 & $100-001-010$ & 010-100-001 & 010-100-001 & 001-010-100 \\
\hline V67 & $100-001-010$ & 010-100-001 & 010-100-001 & 010-100-001 \\
\hline V68 & $100-001-010$ & 010-100-001 & 010-100-001 & $100-001-010$ \\
\hline V69 & $100-001-010$ & 010-100-001 & $100-001-010$ & 001-010-100 \\
\hline V70 & $100-001-010$ & 010-100-001 & $100-001-010$ & 010-100-001 \\
\hline V71 & $100-001-010$ & 010-100-001 & $100-001-010$ & $100-001-010$ \\
\hline V72 & $100-001-010$ & $100-001-010$ & 001-010-100 & 001-010-100 \\
\hline V73 & $100-001-010$ & $100-001-010$ & 001-010-100 & 010-100-001 \\
\hline V74 & $100-001-010$ & $100-001-010$ & 001-010-100 & $100-001-010$ \\
\hline V75 & $100-001-010$ & $100-001-010$ & 010-100-001 & 001-010-100 \\
\hline V76 & $100-001-010$ & $100-001-010$ & 010-100-001 & 010-100-001 \\
\hline V77 & $100-001-010$ & $100-001-010$ & 010-100-001 & $100-001-010$ \\
\hline V78 & $100-001-010$ & $100-001-010$ & $100-001-010$ & 001-010-100 \\
\hline V79 & $100-001-010$ & $100-001-010$ & $100-001-010$ & 010-100-001 \\
\hline V80 & $100-001-010$ & $100-001-010$ & $100-001-010$ & $100-001-010$ \\
\hline
\end{tabular}

\section{References}

1. Blaabjerg, F.; Yang, Y.; Ma, K. Power electronics-Key technology for renewable energy systems—Status and future. In Proceedings of the 2013 3rd International Conference on Electric Power and Energy Conversion Systems, Istanbul, Turkey, 2-4 October 2013; pp. 1-6. [CrossRef]

2. Ahmad, I.; Fandi, G.; Muller, Z.; Tlusty, J. Voltage Quality and Power Factor Improvement in Smart Grids Using Controlled DG Units. Energies 2019, 12, 3444. [CrossRef]

3. Gentvilaite, R.; Kander, A.; Warde, P. The Role of Energy Quality in Shaping Long-Term Energy Intensity in Europe. Energies 2015, 8, 133-153. [CrossRef]

4. Momete, D.C. Analysis of the Potential of Clean Energy Deployment in the European Union. IEEE Access 2018, 6, 54811-54822. [CrossRef]

5. Strzelecki, R.; Sak, T.; Zolov, P.D.; Moradewicz, A.; Grabarek, M. Multi-pulse VSC arrangements with coupled reactors. In Proceedings of the 2016 IEEE 2nd Annual Southern Power Electronics Conference (SPEC), Auckland, New Zealand, 5-8 December 2016; pp. 1-6. [CrossRef]

6. Strzelecki, R.; Sak, T.; Strzelecka, N. Modular multipulse voltage source inverters with integrating coupled reactors. In Proceedings of the 2016 13th Selected Issues of Electrical Engineering and Electronics (WZEE), Rzeszow, Poland, 4-8 May 2016; pp. 1-6. [CrossRef]

7. Strzelecki, R.; Sak, T.; Roslaniec, L.; Dmitrović, Z.P.; Strzelecka, N. Coupled inductors based filter for matrix converters. In Proceedings of the 2016 10th International Conference on Compatibility, Power Electronics and Power Engineering (CPEPOWERENG), Bydgoszcz, Poland, 29 June-1 July 2016; pp. 358-363. [CrossRef]

8. Rodriguez, J.; Lai, J.S.; Peng, F.Z. Multilevel inverters: A survey of topologies, controls, and applications. IEEE Trans. Ind. Electron. 2002, 49, 724-738. [CrossRef]

9. Zhang, J.; Xu, S.; Din, Z.; Hu, X. Hybrid Multilevel Converters: Topologies, Evolutions and Verifications. Energies 2019, 12, 615. [CrossRef] 
10. Ventosa-Cutillas, A.; Montero-Robina, P.; Umbría, F.; Cuesta, F.; Gordillo, F. Integrated Control and Modulation for Three-Level NPC Rectifiers. Energies 2019, 12, 1641. [CrossRef]

11. Pires, V.F.; Monteiro, J.; Silva, J.F. Dual 3-Phase Bridge Multilevel Inverters for AC Drives with Voltage Sag Ride-through Capability. Energies 2019, 12, 2324. [CrossRef]

12. Verdugo, C.; Kouro, S.; Rojas, C.A.; Perez, M.A.; Meynard, T.; Malinowski, M. Five-Level T-type Cascade Converter for Rooftop Grid-Connected Photovoltaic Systems. Energies 2019, 12, 1743. [CrossRef]

13. Chivite-Zabalza, J.; Rodríguez Vidal, M.A.; Izurza-Moreno, P.; Calvo, G.; Madariaga, D. A Large Power, Low-Switching-Frequency Voltage Source Converter for FACTS Applications with Low Effects on the Transmission Line. IEEE Trans. Power Electron. 2012, 27, 4868-4879. [CrossRef]

14. Mysiak, P.; Sleszynski, W.; Cichowski, A. Experimental test results of the $150 \mathrm{kVA}$ 18-pulse diode rectifier with series active power filter. In Proceedings of the 2016 10th International Conference on Compatibility, Power Electronics and Power Engineering (CPE-POWERENG), Bydgoszcz, Poland, 29 June-1 July 2016; pp. 380-383. [CrossRef]

15. Oguchi, K.; Maeda, G.; Hoshi, N.; Kubata, T. Coupling rectifier systems with harmonic cancelling reactors. IEEE Ind. Appl. Mag. 2001, 7, 53-63. [CrossRef]

16. Rodriguez, J.; Rivera, M.; Kolar, J.W.; Wheeler, P.W. A Review of Control and Modulation Methods for Matrix Converters. IEEE Trans. Ind. Electron. 2012, 59, 58-70. [CrossRef]

17. Helle, L.; Larsen, K.B.; Jorgensen, A.H.; Munk-Nielsen, S.; Blaabjerg, F. Evaluation of modulation schemes for three-phase to three-phase matrix converters. IEEE Trans. Ind. Electron. 2004, 51, 158-171. [CrossRef]

18. Friedli, T.; Kolar, J.W. Milestones in Matrix Converter Research. IEEJ J. Ind. Appl. 2012, 1, 2-14. [CrossRef]

19. Szczepankowski, P.; Wheeler, P.; Bajdecki, T. Application of Analytic Signal and Smooth Interpolation in Pulse Width Modulation for Conventional Matrix Converters. IEEE Trans. Ind. Electron. 2019. [CrossRef]

20. Empringham, L.; Kolar, J.W.; Rodriguez, J.; Wheeler, P.W.; Clare, J.C. Technological Issues and Industrial Application of Matrix Converters: A Review. IEEE Trans. Ind. Electron. 2013, 60, 4260-4271. [CrossRef]

21. Strzelecki, R.; Sak, T.; Strzelecka, N. A System for Power Conversion Using Matrix Converters Connected in Parallel. Polish Patent PL 227934, 15 January 2018.

22. Jafari, S.; Miran Fashandi, S.A.; Nikolaidis, T. Modeling and Control of the Starter Motor and Start-Up Phase for Gas Turbines. Electronics 2019, 8, 363. [CrossRef]

23. Gülen, S.C. Gas Turbines for Electric Power Generation; Cambridge University Press: Cambridge, UK, 2019; [CrossRef]

24. Morimoto, M.; Aiba, K.; Sakurai, T.; Hoshino, A.; Fujiwara, M. Position sensorless starting of super high-speed PM Generator for micro gas turbine. IEEE Trans. Ind. Electron. 2006, 53, 415-420. [CrossRef]

25. Szwarc, K.J.; Szczepankowski, P.; Nieznański, J.; Swinarski, C.; Usoltsev, A.; Strzelecki, R. Hybrid Modulation for Modular Voltage Source Inverters with Coupled Reactors. Energies 2020, 13, 4450. [CrossRef]

26. Szczepankowski, P.; Nieznanski, J. Application of Barycentric Coordinates in Space Vector PWM Computations. IEEE Access 2019, 7, 91499-91508. [CrossRef] 